\title{
Lawrence Livermore National Laboratory Quality Assurance Project Plan for National Emission Standards for Hazardous Air Pollutants (NESHAPs), 40 CFR 61, Subpart H
}

L.C. Hall and A.H. Biermann

Lawrence

June 27, 2000

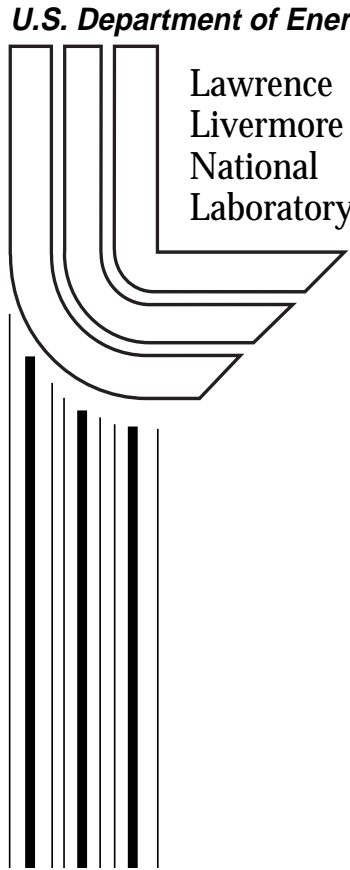




\section{DISCLAIMER}

This document was prepared as an account of work sponsored by an agency of the United States Government. Neither the United States Government nor the University of California nor any of their employees, makes any warranty, express or implied, or assumes any legal liability or responsibility for the accuracy, completeness, or usefulness of any information, apparatus, product, or process disclosed, or represents that its use would not infringe privately owned rights. Reference herein to any specific commercial product, process, or service by trade name, trademark, manufacturer, or otherwise, does not necessarily constitute or imply its endorsement, recommendation, or favoring by the United States Government or the University of California. The views and opinions of authors expressed herein do not necessarily state or reflect those of the United States Government or the University of California, and shall not be used for advertising or product endorsement purposes.

Work performed under the auspices of the U. S. Department of Energy by the University of California Lawrence Livermore National Laboratory under Contract W-7405-Eng-48.

This report has been reproduced directly from the best available copy.

Available to DOE and DOE contractors from the

Office of Scientific and Technical Information

P.O. Box 62, Oak Ridge, TN 37831

Prices available from (423) 576-8401

http://apollo.osti.gov/bridge/

Available to the public from the National Technical Information Service

U.S. Department of Commerce 5285 Port Royal Rd., Springfield, VA 22161 http://www.ntis.gov/

OR

Lawrence Livermore National Laboratory Technical Information Department's Digital Library http://www.llnl.gov/tid/Library.html 


\section{Lawrence Livermore National Laboratory Quality Assurance Project Plan for}

National Emission Standards for Hazardous Air Pollutants (NESHAPs),
40 CFR 61, Subpart H

Linda C. Hall and Arthur H. Biermann

June 27, 2000 


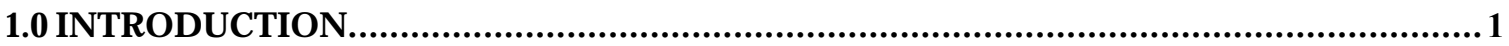

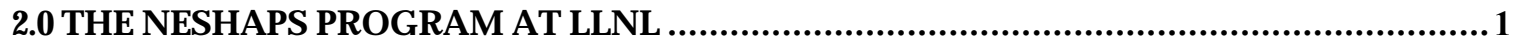

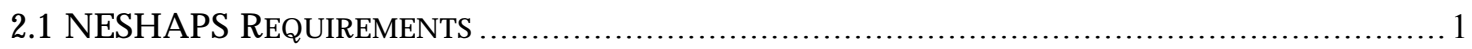

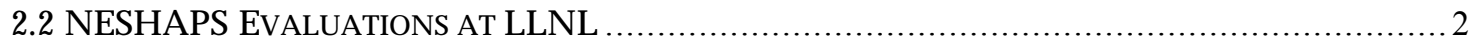

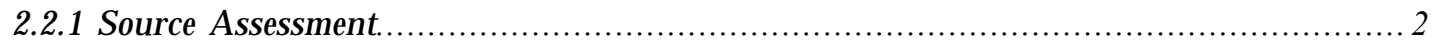

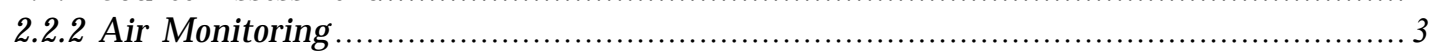

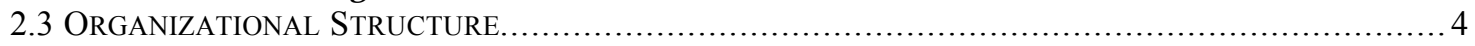

2.3.1 Laboratory-Wide Organizations.............................................................. 4

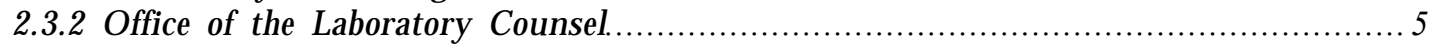

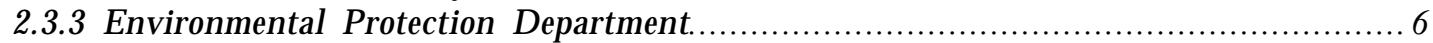

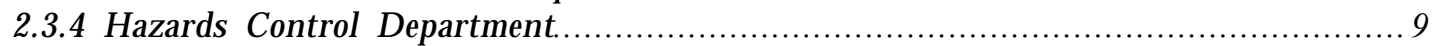

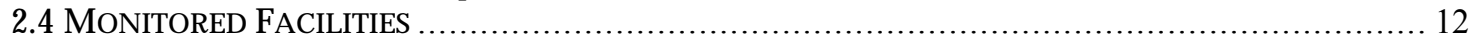

2.4.1 NESHAPs Agreements of Roles and Responsibilities (NARR)......................... 12

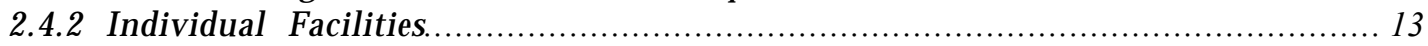

3.0 RESPONSE TO RELEASES FROM UNPLANNED OPERATIONS …............................. 15

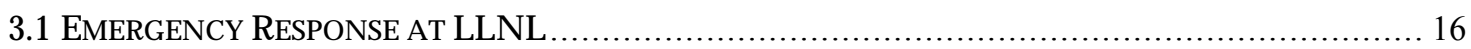

3.1.1 EPD Emergency Response Program ....................................................... 17

3.2 EMERGENCY RESPONSE PLANS FOR MONITORED FACILITIES ........................................ 19

3.2.1 Buildings 175, 177, and 491-AVLIS Facilities............................................ 19

3.2.2 Building 251- Heavy Element Facility..................................................... 19

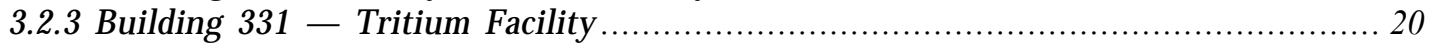

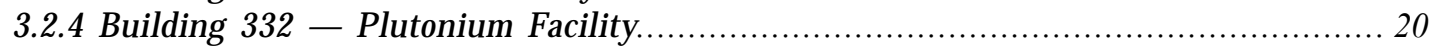

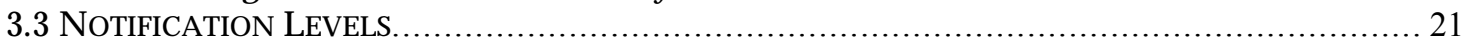

4.0 AIR EFFLUENT SAMPLING LOCATIONS.................................................................. 22

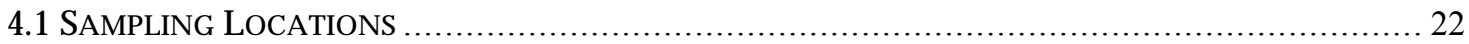

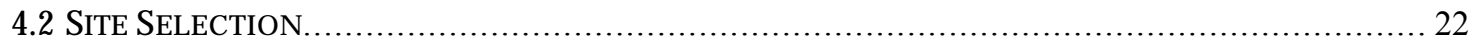

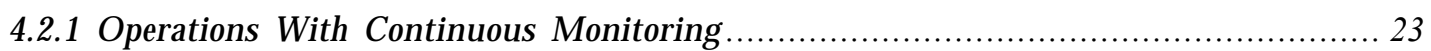

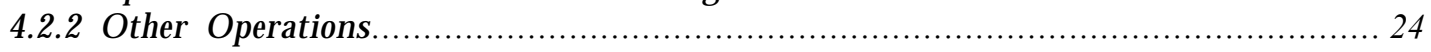

5.0 DESCRIPTION OF SAMPLING PROBES AND REPRESENTATIVENESS OF THE

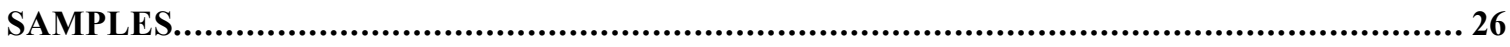

6.0 CONTINUOUS AIR MONITORING AND SAMPLING SYSTEMS ................................ 28

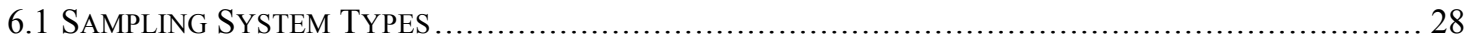

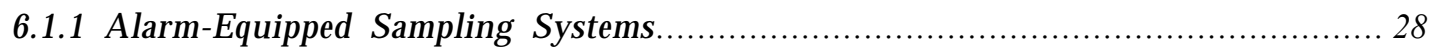

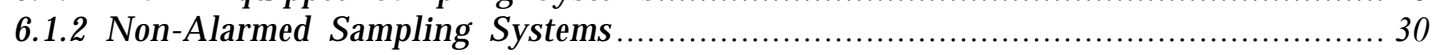

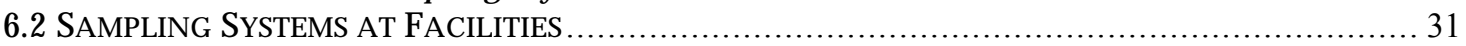

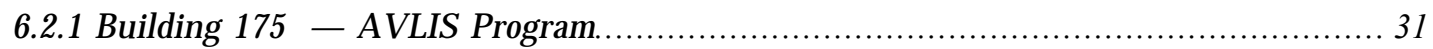

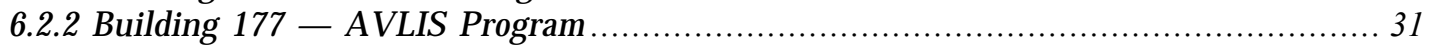

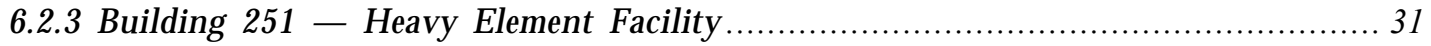

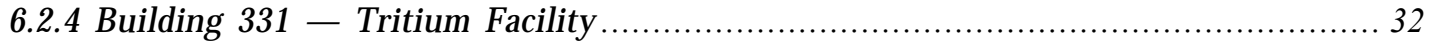

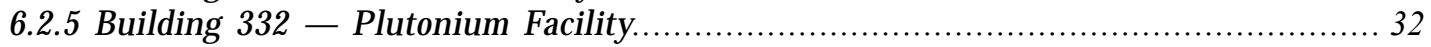

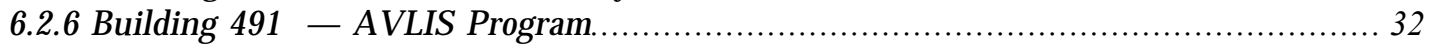


6.3 High EfFiciency Particulate Air (HEPA) Filtration............................................ 33

7.0 LABORATORY ANALYSIS PROCEDURES AND STANDARDS.................................. 33

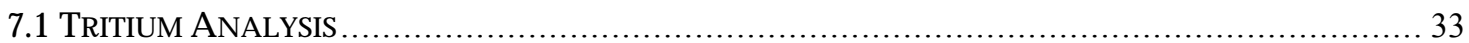

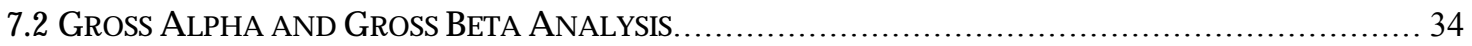

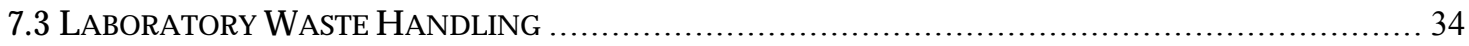

8.0 SAMPLE FLOW RATE MEASUREMENT SYSTEM, CALIBRATION PROCEDURES, AND

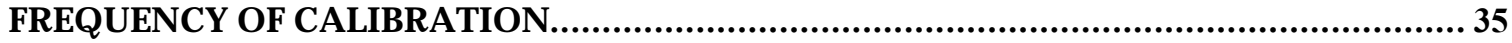

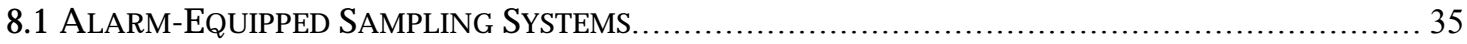

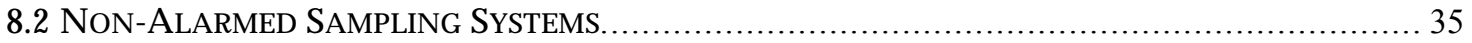

9.0 EFFLUENT FLOW RATE MEASUREMENT PROCEDURES ............................................ 36

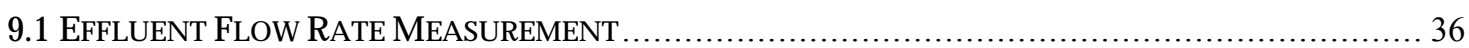

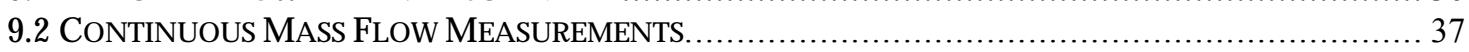

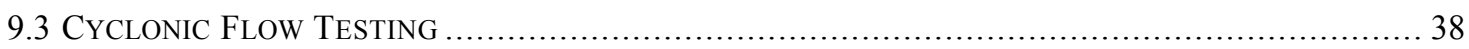

10.0 NESHAPS QUALITY ASSURANCE PROGRAM......................................................... 38

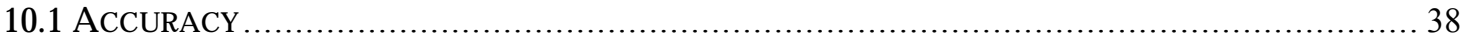

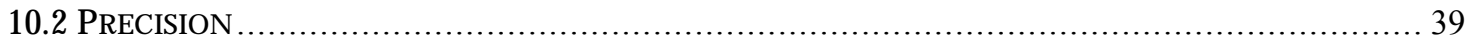

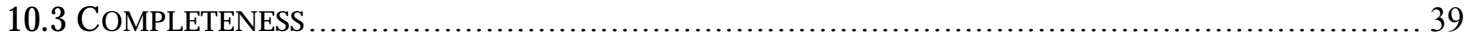

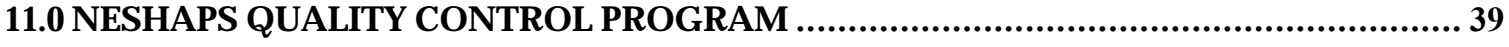

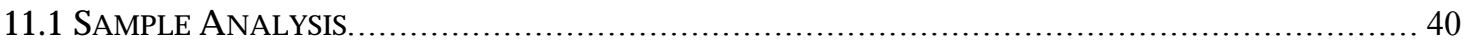

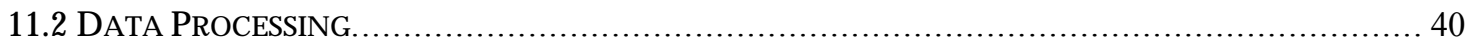

12.0 SAMPLE HANDLING AND CUSTODY PROVISIONS............................................ 41

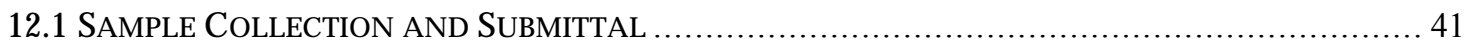

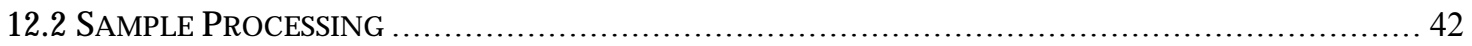

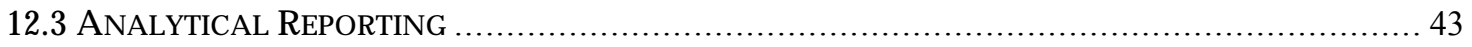

13.0 DATA MANAGEMENT AND DATA ANALYSIS .....................................................4

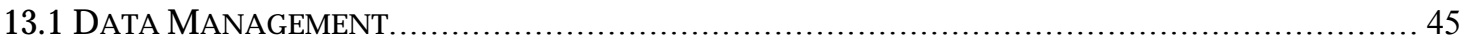

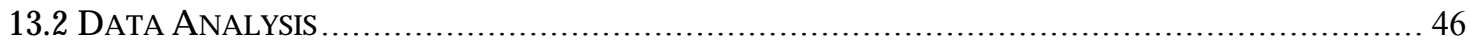

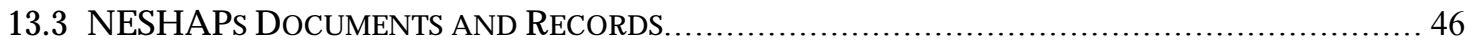

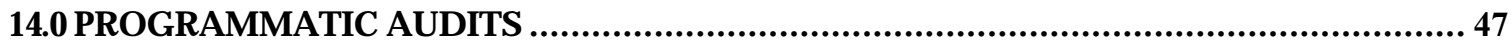

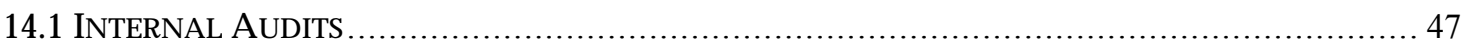

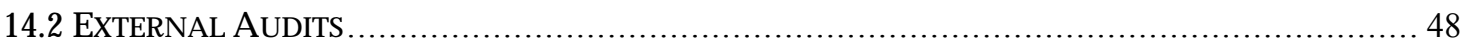

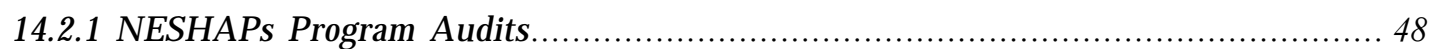

14.2.2 HCD Laboratory Audits......................................................................... 49

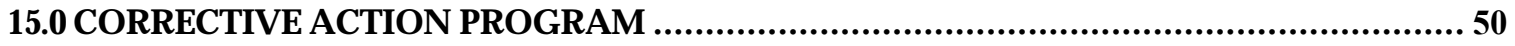

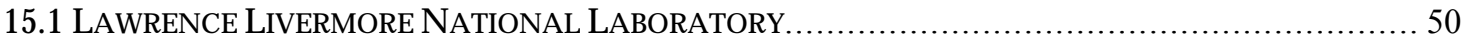

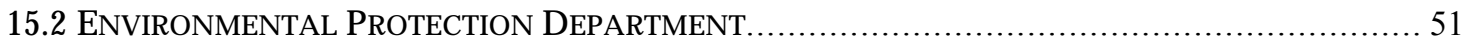

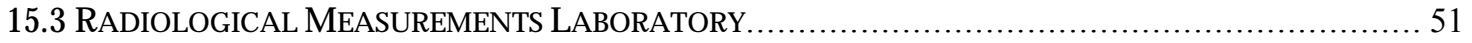

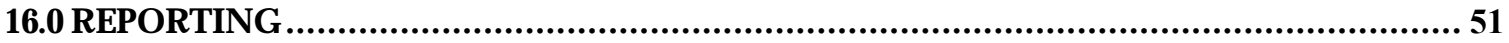

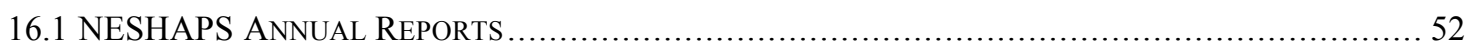

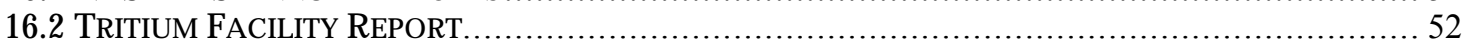

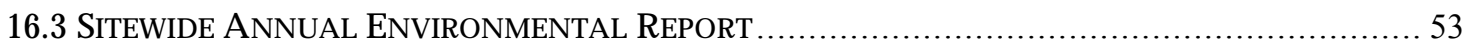

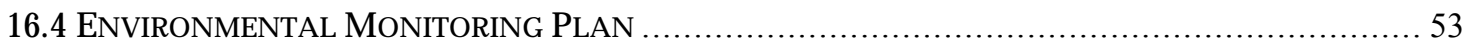

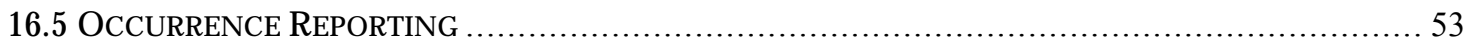


17.0 DEPARTMENT OF ENERGY QUALITY ASSURANCE PROGRAM REQUIREMENTS..... 54

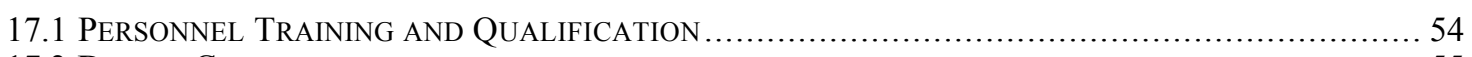

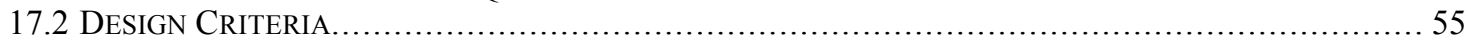

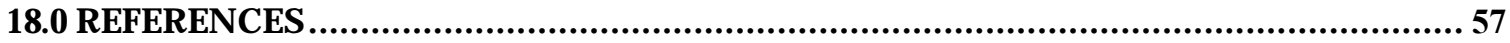

APPENDIX A. DEPARTMENT OF ENERGY QUALITY ASSURANCE PROGRAM

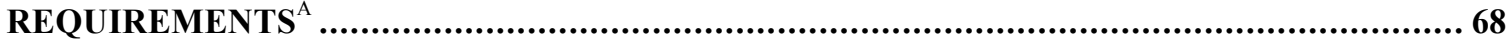




\subsection{Introduction}

As a Department of Energy (DOE) Facility whose operations involve the use of radionuclides, Lawrence Livermore National Laboratory (LLNL) is subject to the requirements of 40 CFR 61, the National Emission Standards for Hazardous Air Pollutants (NESHAPs). Subpart H of this Regulation establishes standards for exposure of the public to radionuclides (other than radon) released from DOE Facilities (Federal Register, 1989). These regulations limit the emission of radionuclides to ambient air from DOE facilities (see Section 2.0).

Under the NESHAPs Subpart H Regulation (hereafter referred to as NESHAPs), DOE facilities are also required to establish a quality assurance program for radionuclide emission measurements; specific requirements for preparation of a Quality Assurance Program Plan (QAPP) are given in Appendix B, Method 114 of 40 CFR 61. Throughout this QAPP, the specific Quality Assurance Method elements of 40 CFR 61 Subpart H addressed by a given section are identified. In addition, the US Environmental Protection Agency (US EPA) (US EPA, 1994a) published draft requirements for QAPP's prepared in support of programs that develop environmental data. We have incorporated many of the technical elements specified in that document into this QAPP, specifically those identified as relating to measurement and data acquisition; assessment and oversight; and data validation and usability.

This QAPP will be evaluated on an annual basis, and updated as appropriate.

\subsection{The NESHAPs Program at LLNL}

This section describes the principal regulatory requirements of the NESHAPs regulations and discusses the components of the NESHAPs program at LLNL. Sub-section 2.3 addresses the requirements of paragraph 4.1, Appendix B, Method 114 of 40 CFR 61, and provides information on the organizational structure, functional responsibilities, level of authority, and lines of communication of the NESHAPs program at LLNL. The NESHAPs program is also described in Volume III of LLNL's Environmental Safety and Health (ES\&H) Manual (LLNL, 2000a).

\subsection{NESHAPS Requirements}

NESHAPs regulations, promulgated in 1991, limit the emission of radionuclides to ambient air from DOE facilities to levels resulting in a cumulative annual effective dose equivalent (EDE) of $10 \mathrm{mrem}(100 \mu \mathrm{Sv})$ to any member of the public. The NESHAPs regulations also require that monitoring of facility radionuclide air effluent be performed if the potential off-site dose equivalent from a specific emission point is greater than 0.1 
mrem/y $(1 \mu S v / y)$, as calculated using an US EPA-mandated air dispersion dose model, utilizing the assumption that no emission control devices are in place. Since formal NESHAPs-mandated compliance assessments were instituted at LLNL in 1991, dose calculations have consistently demonstrated levels of public exposure well below the primary regulatory standard of 10 $\mathrm{mrem} / \mathrm{y}(100 \mu \mathrm{Sv} / \mathrm{y})$.

\subsection{NESHAPS Evaluations at LLNL}

The NESHAPs program at LLNL is interdisciplinary, with participation from all LLNL organizations whose operations have the potential to release radionuclides to the atmosphere. The Terrestrial Atmospheric Monitoring and Modeling (TAMM) Group within the Operations and Regulatory Affairs Division, Environmental Protection Department (EPD) has the principle responsibility for the administration of 40 CFR 61 Subpart H. The TAMM Group has responsibility for evaluating all LLNL operations having the potential for radiological air emissions to determine the need for continuous monitoring; establishing emission monitoring systems (when required) and evaluating and interpreting the resulting analytical data; conducting the annual evaluation and verification of radionuclide usage inventory data for completing dose assessment modeling runs; and completing all programmatic dose calculations. The TAMM Group presents NESHAPs monitoring data in several periodic reports, including an annual report devoted solely to the NESHAPs program. The TAMM Group is also responsible for overall program quality assurance, and represents the Laboratory in any technical reviews, program audits, or interactions with regulatory agencies (see Section 2.3.3.1).

\subsubsection{Source Assessment}

At LLNL, point sources at both the Livermore site and Site 300 having the potential for radiological air emissions are evaluated to determine the need for continuous monitoring. For unmonitored sources, annual radionuclide release estimates are based on radionuclide usage inventory data and US EPA physical state and abatement release fractions (radionuclide releases from continuously monitored facilities are based on measured emissions).

Radionuclide usage inventory data are provided by experimenters and facility managers, following a protocol designed and administered by the TAMM Group. A full (100\%) inventory is conducted every three years; only the "key" Livermore site facilities, defined as those in a ranked list that collectively accounted for $90 \%$ (or greater) of the previous year's Livermore site radiological dose to members of the public, are reinventoried annually. In addition, all new (or newly-modified) operations with a potential to release radionuclides to the atmosphere are inventoried, and radionuclide inventories for all Site 300 explosives experiments involving radionuclides 
are newly evaluated each year (LLNL, 2000b). From these inventory data, and from measurement of actual releases to air from monitored buildings, doseassessment modeling is conducted.

NESHAPs dose calculations are also completed annually for diffuse or non-point sources (diffuse sources of radionuclide emissions are typically area sources external to buildings). The nature and magnitude of sources of this type are difficult to quantify; there are no US EPA-mandated methods for estimation or measurement. Historically, NESHAPs evaluations at LLNL have considered diffuse sources at both the Livermore site and at Site 300. At the Livermore site, emission estimates and radiological dose calculations from diffuse sources rely on either personnel knowledge and environmentalsurveillance data; radiological usage inventory data and air-dispersion modeling; or ambient-air monitoring. Diffuse sources at Site 300 include five areas of surface or subsurface tritium contamination. For these areas, tritium exposure is estimated based on environmental monitoring data obtained at a sampling location that represents the site-wide maximally-exposed individual. In addition, depleted uranium has been used as a component of explosives-test assemblies at Site 300, and is present as a contaminant of surface soil. The dose attributed to resuspended depleted uranium also is based on environmental surveillance monitoring.

The annual NESHAPs dose assessment considers the total contribution from all point sources and diffuse sources at the Livermore site or Site 300. This assessment yields an EDE to the site-wide maximally-exposed individual (SW-MEI). The SW-MEI is defined as the hypothetical member of the public at a single residence, school, business, or office who receives the greatest LLNL-induced EDE from the combination of all radionuclide source emissions. The SW-MEI calculation considers the dose to a hypothetical individual from all pathways, including inhalation of air and ingestion of foodstuffs and drinking water, as well as external exposures through irradiation from contaminated ground and immersion in contaminated air resulting from radionuclides released to the air.

\subsubsection{Air Monitoring}

To comply with 40 CFR 61, Subpart H, LLNL maintains a network of monitoring systems that measure radionuclide emissions from certain routine operations at the Laboratory. Currently, six facilities, Buildings 175, $177,251,331,332$, and 491 , are continuously monitored from one or more discharge points. The radiological continuous sampling systems in these buildings consist of either filter-type continuous aerosol collectors (to measure gross alpha or gross beta activity); alarm-equipped continuous air monitors (for detection of gross alpha activity); and molecular sieves and alarm-equipped ion chambers (for the detection of tritium). Data acquired from the filter-type aerosol collectors and the molecular sieves are also used in environmental reporting. The alarm-equipped devices i.e., continuous air

monitors and ion chambers, are facility-specific safety systems; they are not 
part of the NESHAPs program, and data from these measurement systems are not used for environmental reporting.

LLNL also conducts air surveillance monitoring to evaluate compliance with local, state, and federal regulations, and DOE Orders, and to ensure that human health and the environment are protected from airborne radionuclide emissions. With respect to NESHAPs, air surveillance measurements are used to estimate radionuclide releases (and calculate the dose) from certain diffuse sources where it is difficult to otherwise quantify emission rates. Surveillance measurements also provide a degree of redundancy to the NESHAPS monitoring of key buildings in the event of sampling equipment failure. Air surveillance monitors will also detect even minor emissions from non-monitored facilities, and, in the case of an accidental release, data from surveillance monitoring is available to supplement measurement data from continuous monitors or other equipment. To monitor radiological particulates, LLNL maintains eight samplers on the Livermore site, nine in the Livermore Valley, eight at Site 300, and one in the City of Tracy. In addition, samplers that measure tritium in air operate continuously at eleven locations on the Livermore site, at six locations in the Livermore Valley, and at one location at Site 300 (see Harrach et al., 1998; Tate et al., 1999).

\subsection{Organizational Structure}

This sub-section documents the requirements of paragraph 4.1 of Appendix B, 40 CFR 61 Subpart $\mathrm{H}$ by describing the organizational structure, functional responsibilities, levels of authority, and lines of communication for all activities related to the radionuclide air effluent monitoring program.

\subsubsection{Laboratory-Wide Organizations}

Lawrence Livermore National Laboratory, its facilities, programs, and staff are organized into directorates and the Laboratory Site Operations (LSO) organization. The directorates are each headed by an Associate director (AD) who reports to both a Deputy Director and to the Director of the Laboratory. The LSO is headed by the Laboratory Site Manager, who reports to the Deputy Director of Operations and to the Director of LLNL. All directorates at LLNL that have operations with the potential for release of radionuclides to the air share responsibility for compliance with 40 CFR 61 Subpart $H$.

LLNL has a comprehensive Environment Safety and Health (ES\&H) program; that program has recently been integrated with the DOE's Integrated Safety Management System (ISMS) program. The principles, policies, and procedures of the combined ES\&H/ISMS program at LLNL are described in the Laboratory's ES\&H Manual (LLNL, 2000c).

Implementation of the ES\&H program is a line management responsibility that is delegated from the Director to each $\mathrm{AD}$ and then through each AD's program or management chain to employees. The Deputy 
Director for Operations advises the Director on ES\&H policies and institutional issues, with input from the office of the Laboratory Counsel, Laboratory Site Operations, the Council for Strategic Operations (CSO, described below), and the ES\&H Working Group (ES\&H WG, described below), and oversees the effectiveness of activities and programs to implement these policies. The Assurance Review Office performs institutional-level oversight of ES\&H program implementation by the directorates.

The CSO was created by the Laboratory Director, and is comprised of a group of Associate Directors and the Laboratory Controller. The purpose of the CSO is to provide Laboratory-wide strategic direction and tactical planning. The Council works to develop and integrate the 'best-in-class', costeffective administrative and operational management systems that enable and support the Laboratory's science and technology mission. The ES\&H WG supports the Deputy Director for Operations. The ES\&H WG is composed of assurance managers from each directorate, the heads of the Hazards Control Department (HCD), EPD, the Health Services Department, and the Quality Assurance Support Office, as well as the ES\&H representative from the Director's Office. Among the principal responsibilities of the ES\&H WG are to address ES\&H (and quality assurance) issues raised by programs, to prepare recommended actions for consideration, to review generic or institutional ES\&H or quality assurance issues, and initiate policy development or change. Assurance Managers are appointed by each AD, and each is directly responsible to the $\mathrm{AD}$ or the appropriate Deputy $\mathrm{AD}$. The primary role of the Assurance Manager is to provide oversight of the directorate's ES\&H activities for the AD (LLNL, 2000c). The Assurance Manager is also responsible for assisting in the development of directorate ES\&H plans and procedures; for providing oversight of the directorate's line organizations, facilities, and activities, to ensure appropriate implementation of the ES\&H program within the directorate, and for performing independent assessments of the ES\&H program within the directorate (LLNL, 2000c).

\subsubsection{Office of the Laboratory Counsel}

Staff of LLNL's Office of the Laboratory Counsel are responsible for negotiations with, and response to, the US EPA regarding compliance and/or enforcement of NESHAPs regulations. Legal staff are available to review proposed programmatic activities for compliance with NESHAPs regulations, and advise both NESHAPs and LLNL program staff regarding interpretation and implementation of these regulations. The Office of the Laboratory Counsel is also responsible for responding to any formal legal challenge regarding LLNL's compliance with NESHAPs regulations. 


\subsubsection{Environmental Protection Department}

Within the LSO, the Environmental Protection Department (EPD) is responsible for providing technical assistance to Facilities to ensure environmental compliance and to assist Laboratory organizations to conduct their work in an environmentally acceptable manner. The Operations and Regulatory Affairs Division (ORAD) within EPD provides Laboratory-wide oversight of environmental compliance. Three separate groups within ORAD are directly involved in the NESHAPs program at LLNL; the Environmental Evaluations Group (EEG), the Environmental Operations Group (EOG), and the Terrestrial and Atmospheric Monitoring and Modeling (TAMM) Group. (The TAMM Group is responsible for overall NESHAPs program management and has extensive responsibilities that are discussed separately in section 2.3.3.1.) Additionally, EPD has Environmental Support Teams (EST's) that provide a formal communication forum within EPD on programmatic issues related to compliance with environmental regulations. EPD, through the EOG, also participates in inter-disciplinary, interdepartmental Environment, Safety, and Health Teams (see 2.3.4.2). An organizational chart for EPD is shown in Figure 1.

The EEG provides support to LLNL programs and facilities on implementing the requirements of DOE Orders and both federal and state laws and regulations that pertain to environmental impact evaluations, and all aspects of natural resource protection. This group evaluates all proposed new or modified operations at LLNL for compliance with the National Environmental Policy Act (NEPA), and prepares written assessments of each new or modified operation at LLNL. These assessments are a primary avenue for the transfer of information from experimental programs to the NESHAPs program.

The EOG conducts facility audits, assists in characterizing waste streams and managing wastes, provides incident response services, and evaluates new operations and facilities for environmental concerns. Analysts from the EOG serve as Chairperson of each of the four EST's (see following), and also participate on the Laboratory's ES\&H Teams.

Environmental Support Teams are comprised of representatives from each of the three Divisions of EPD (ORAD, the Environmental Restoration Division, and the Hazardous Waste Management Division). The primary responsibilities of these Teams are to ensure communication and teamwork among the different environmental disciplines, between the EST's and the ES\&H Teams, and to provide environmental support to all LLNL programs (LLNL, 1993a). These teams represent a principal route for providing information to the NESHAPs program.

In addition to EPD, all of the facilities that use or store radionuclides, the HCD, and the Office of the Laboratory Counsel participate in the NESHAPs program. The relationship between each of these organizations 


\section{ENVIRONMENTAL PROTECTION DEPARTMENT \\ Department Head \\ Deputy Department Head}

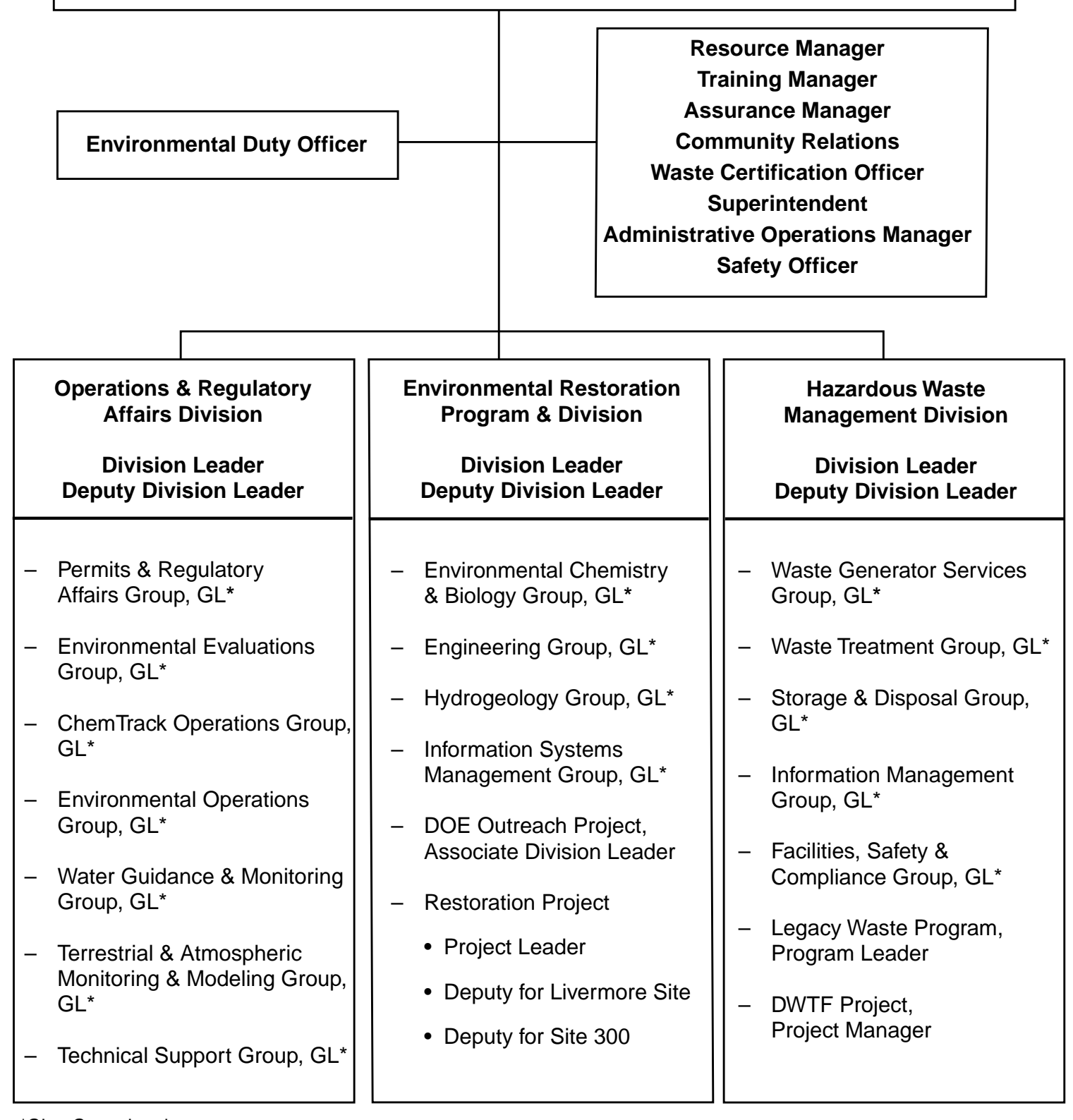

${ }^{*} \mathrm{GL}=$ Group Leader

Figure 1. Organizational Structure of the LLNL Environmental Protection Department. 
regarding the NESHAPs program is depicted in Figure 2. A NESHAPs Agreement of Roles and Responsibilities (NARR) between HCD and EPD delineates the responsibilities of each department within the context of the NESHAPs program (2000d). NARRs between EPD and LLNL programs with monitored facilities are discussed in sub-section 2.4.1 (LLNL, $2000 \mathrm{e}, \mathrm{f}, \mathrm{g}, \mathrm{h}$ ).

\subsubsection{Terrestrial and Atmospheric Monitoring and Modeling Group}

The Terrestrial and Atmospheric Monitoring and Modeling (TAMM) Group in the Operations and Regulatory Affairs Division of EPD is responsible for overall management of the NESHAPs program. The TAMM Group is responsible for the implementation, administration, and fiscal management of the NESHAPs program. Specifically, the TAMM Group is responsible for informing the facilities, programs, and the HCD of regulatory requirements regarding air effluent sampling for radionuclide emissions; evaluating all LLNL operations having the potential for radiological air emissions to determine the need for continuous monitoring; an annual

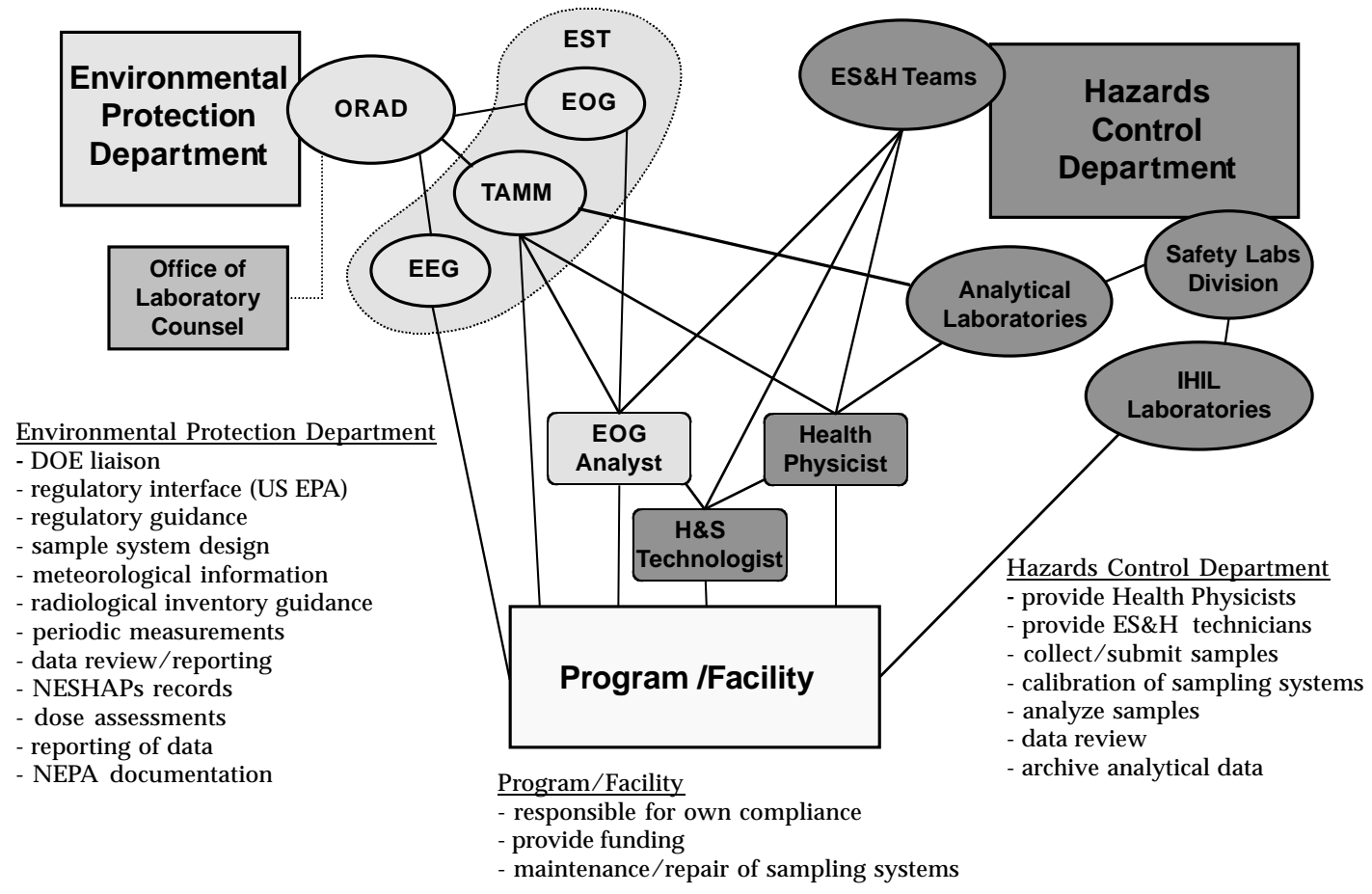

Figure 2. Cooperative relationships between LLNL organizations involved in the radionuclide air effluent monitoring program under NESHAPs. 
evaluation and verification of radionuclide usage inventory data; annual assessments of radiological dose to the public; providing guidance regarding the design of air sampling systems for continuously monitored facilities; the development and implementation of procedures relevant to the sampling program, including procedures for sample collection, sample flow calibration, and air sampling system inspections; making measurements of the effluent air flow from facility exhaust systems with air samplers; inspecting, maintaining, and calibrating the electronic data collection systems for stack velocity probes; identification of problems and issues regarding the sampling systems and their results as well as the initiation of appropriate measures to resolve them; periodic confirmatory measurements; verification of analytical data; statistical analyses of program data; preparation of programmatic reports including this QAPP; program data management including the maintenance of archived records (for at least five years) of sampling results, air effluent concentrations, and calculated emissions; and for the preparation of reports and other documents to describe the program and sampling systems (LLNL, 1992a, 1993b, 2000 d,e,f,g,h).

The TAMM Group serves as the principal liaison between LLNL and both the US Department of Energy (DOE) and the US EPA for all issues which pertain to the radiological NESHAPs program (US DOE, 1995a). TAMM Group staff review proposed programmatic activities for compliance with NESHAPs regulations, and advise LLNL program staff regarding interpretation and implementation of these regulations. The TAMM Group is also responsible for responding to inspections and reviews of the air effluent sampling program by LLNL, US DOE, US EPA, and other regulatory agencies. Within the context of the NESHAPs program, the TAMM Group is responsible for determining the potential impacts of radionuclide releases from LLNL, and environmental surveillance monitoring of air and vegetation. In support of these activities, the TAMM Group is also responsible for the collection, analysis, and use of meteorological data. Environmental Analysts from the TAMM Group of EPD participate in the EST's which provide technical support to LLNL programs in all aspects of environmental compliance. As members of the EST's, TAMM personnel are responsible for providing guidance on radionuclide air effluent monitoring, assessment of radionuclide emissions, NESHAPs compliance for new and existing projects, and review of NEPA documentation (prepared by the EEG of EPD) regarding new programmatic activities involving the use of radionuclides.

\subsubsection{Hazards Control Department}

Within the context of NESHAPs, HCD also has significant responsibilities. Five organizations within HCD are directly involved in the NESHAPs program; the Safety Laboratories Division and the four ES\&H Teams. The Emergency Management Division is also a part of HCD. This Division has significant responsibilities in emergency response and emergency 
preparedness, potentially including those related to the unplanned release of radionuclides. Those responsibilities are discussed in Section 3.0, Response to Releases from Unplanned Operations.

\subsubsection{Safety Laboratory Division}

The Safety Laboratory Division consists of eight laboratories; two of the laboratories, the Analytical Laboratory (AL) and the Radiological Measurements Laboratory (RML) are essential to the NESHAPs program for sample analysis. Technical staff of the AL are responsible for the extraction of tritium from molecular sieves, and for providing this material to the RML for analysis, along with the corresponding sample receipt and handling records (see Section 12.0). Staff of the RML perform the routine analyses of tritium; the laboratory is also responsible for analyses of air filter samplers for gross alpha and gross beta activity. Specific responsibilities of both laboratories include appropriate sample handling and maintenance of custody; record keeping; instrument calibration; prevention of contamination; maintenance of the purity of reagents, chemicals, and analytical standards; control of analytical performance; and timely and accurate data reporting to TAMM/EPD (HCD, 1996a,b; LLNL, 2000d). RML is responsible for maintaining archived air effluent concentration results for at least five years. The quality control manual for the AL (HCD 1996b) and the quality assurance implementation plan for the RML (HCD, 1996a) document the responsibilities of the laboratories and of their staff.

A third laboratory, the Industrial Hygiene Instruments Laboratory (IHIL) conducts tests of high-efficiency particulate air (HEPA) filters for filter efficiency and integrity. Staff of the IHIL are responsible for testing HEPA filters in accordance with procedures established in IHIL (1996). The IHIL is also responsible for maintaining a written record of HEPA test results, and for providing a written report of these results to seither the responsible health physicist or industrial hygienist (and to other individuals as appropriate) (IHIL, 1996). Although HEPA filters are not maintained solely in support of NESHAPs, they are an integral part of the Laboratory's environmental compliance program. A fourth laboratory, the Radiation Calibration Laboratory [formerly the Calibration and Standards Laboratory (CSL)], is responsible for the routine (annual) calibration of the continuous air monitors (CAMs) used to sample stack air effluent in certain monitored facilities. Calibration of these samplers insures the detection of alpha particles of specific energy. The calibration process follows established procedures (CSL, 1996).

The Safety Laboratories Division is responsible for conducting a quality assurance program that encompasses sample analysis for the radiological air effluent samples. The Division is also responsible for ensuring that the AL and the RML participate in the DOE Environmental Monitoring Laboratory inter-comparison studies program. 


\subsubsection{Environment Safety and Health (ES\&H) Teams}

Professional environmental, health, and safety support to facilities is provided by ES\&H Teams in the areas of industrial hygiene, industrial safety, health physics, fire protection, criticality safety (where applicable), pressure safety (where applicable), and environmental protection. ES\&H Teams are administered by HCD; Team Leaders are HCD staff, as are specialists in health physics, industrial hygiene, and industrial safety, as well as Health and Safety Technologists who are assigned to facilities by the ES\&H Teams. Other Team members are from the Health Services Department, and the Environmental Protection Department.

The responsibilities of the ES\&H Teams are described in Volume 1, Part 2, Chapter 1.3.10 of LLNL's ES\&H Manual (LLNL, 2000i), as well as in Facility Safety Procedure documents, and in Discipline Action Plans (DAPs) for each facility. DAPs specifically delineate all known radiological hazards that exist in a facility, and provide a formalized plan for monitoring and controlling the hazards so that any radiation doses to personnel are maintained as low as reasonably achievable (ALARA) below limits specified in DOE Order 5400.5 (US DOE, 1993a) and 10 CFR 835 (Federal Register, 1993a). The DAP for each facility also includes a set of Field Support Instructions. Each Instruction covers a specific activity such as the periodic exchange of continuous air filter samplers, and provides detailed procedural instructions for the Health and Safety Technologist to follow when conducting the particular activity (see Sections 4 and 5).

The ES\&H Team provides assistance in all safety and environmental matters to the users of the facilities. Responsibilities of the ES\&H Team include providing technical support and consultation to authorizing organizations before, during, and after all operations, including emergencies; assisting authorizing organizations with identifying and analyzing ES\&H hazards, and in meeting mandatory requirements; providing guidance to authorizing organizations about developing and reviewing safety-related plans, procedures, and documents; independently performing ES\&H surveillance of, and feedback on, planned and ongoing operations, facilities, equipment, and procedures, and recommending corrective actions to the cognizant management; and monitoring the work environment to identify areas of non-compliance with ES\&H requirements (LLNL, 2000j). In addition, the ES\&H Teams are responsible for the collection of routine air effluent monitoring samples and for the submittal of air samples to the AL and/or RML for analysis. These latter activities are typically performed by the Health and Safety Technologist assigned to a given facility. The ES\&H Teams are also responsible for providing technical support for sampler flow calibration and for routine inspections of the sampling systems (LLNL, 2000d). 


\subsection{Monitored Facilities}

This section provides information on each of the facilities at LLNL where continuous radionuclide air effluent monitoring is conducted. For each facility, the administrative structure and responsibilities relevant to the NESHAPs program are described, and the specific ES\&H Team which provides technical support to the facility is identified.

\subsubsection{NESHAPs Agreements of Roles and Responsibilities (NARR)}

NESHAPs Agreements of Roles and Responsibilities (NARRs) between EPD and the Lasers Directorate (LLNL, 2000e), the Heavy Element Facility (LLNL, 2000f), the Tritium Facility (LLNL, 2000g), and the Plutonium Facility (LLNL, 2000h) identify the responsibilities of each facility or the responsible directorate with respect to radionuclide air effluent monitoring and sampling conducted to maintain compliance with 40 CFR 61 Subpart H. These Facility responsibilities are to delineate safety responsibilities, and to provide guidance and review of air sampling system design, sampling procedures, and sampling schedules; provide for the installation of new air effluent sampling systems (when required); provide support (as necessary) to the cognizant ES\&H Team to perform the procedures for continuous sampling; provide routine supplies associated with the continued operation of stack sampling systems; retain a supply of spare parts for the stack sampling systems; maintain and repair the velocity probes and stack sampling systems; provide for stack access; inform EPD of non-routine releases and significant new operations; and review reports of air effluent results, especially those provided to outside agencies.

Under these NARRs, EPD is responsible for informing the facilities and programs of regulatory requirements regarding air effluent sampling for radionuclide emissions; providing assessments of, and design criteria for, air sampling systems; developing and implementing instructions for stack "passive" air monitors (as appropriate), including those for sample collection, sample flow calibration, and air sampling system inspections; reviewing and tracking sample results and other data relevant to air effluent sampling; making measurements of the effluent air flow from those facility exhaust systems having air samplers; inspecting, maintaining, and calibrating the electronic data collection systems for stack velocity probes; identifying problems and issues regarding the sampling systems and their results, and initiating appropriate measures to resolve them; performing periodic confirmatory sampling according to 40 CFR 61 Subpart H; preparing documentation to describe the sampling systems and reporting sampling results within programmatic and other documents; archiving pertinent records of sampling results, air effluent concentrations, and calculated emissions for five years; and responding to regulatory agency and DOE inspections and reviews of the air effluent sampling effort as required. 


\subsubsection{Individual Facilities}

Information on the operations authorized for a given facility; responsibilities and authorities of facility staff and support personnel; safety regulations, operational hazards and environmental concerns and their controls; maintenance and quality assurance requirements for building safety systems and programmatic equipment; and emergency controls are contained within Facility Safety Plans (FSPs), Operational Safety Plans (OSPs), and project-specific, safety integration work sheets (IWSs) in accordance with LLNLs Integrated Safety Management Program (LLNL, 2000c,i). Details of each facility's organizational structure, functional responsibilities, levels of authority, and lines of communication are described here.

\subsubsection{Advanced Vapor Laser Isotope Separation Program (AVLIS) Facilities; Buildings 175, 177, and 491}

From 1973 to 1999, the AVLIS Program at LLNL utilized laser technology to separate U235 from other uranium isotopes to produce fuel for nuclear reactors. The program was administered by the Lasers Directorate, and funded by the United States Enrichment Corporation (USEC). Three of the buildings used by the program, Buildings 175, 177, and 491, are monitored under NESHAPs.

In June of 1999, USEC announced the shutdown of the AVLIS program. Since that time, DOE, LLNL, and the USEC have collaborated to develop a comprehensive plan that addresses the shutdown, surveillance, and maintenance of the buildings and facilities formerly used by the program. The resulting plan (LLNL, 1999a) describes each of the affected buildings, identifies the individual(s) responsible for meeting the commitments of the plan, identifies any hazards and their mitigation, lists the surveillance and maintenance requirements, and provides a building-specific list of all relevant safety documentation.

Buildings 175, 177, and 491 are in "Shutdown", a term that encompasses all activities designed to render the equipment and facility safe, and preserve its basic functionality and operational potential during an inactive state (LLNL, 1999a). The air effluent monitoring systems in these three buildings, established for compliance with NESHAPs, will continue to operate during "Shutdown". Historically, ES\&H Team 2 provided personnel in these buildings with assistance in all health, safety, and environmental matters. The Team operated, and will continue to operate, under responsibilities listed in specific Facility Safety Plans (LLNL 1997a, 1997b).

\subsubsection{Building 251 - Heavy Element Facility}

The Heavy Element Facility (B251), a Category 3 non-reactor nuclear facility which is in Program Standby Mode, is operated for LLNL by the 
Physics Directorate. Operations are limited to storage and disposal of radioactive materials, cleanup and deactivation of laboratories and equipment, and maintenance activities.

The Associate Director (AD) of Physics receives institutional funds for maintaining the facility, provides the personnel to support the ES\&H program, and is responsible for the preparation of the Facility Safety Plan (LLNL, 1997c). The Deputy AD for Operations is responsible for the oversight and coordination of planning, and the independent ES\&H Assurance function within the Physics Directorate. The Deputy AD for Operations is responsible for ensuring that LLNL and Physics Directorate policies are implemented, assessing operations for safe and environmentally sound practices, and ensuring that Integrated Safety Management is implemented in the facility (LLNL, 1999b).

The Physics Assurance Manager is responsible for determining the applicability of LLNL and Physics Directorate policies and Best Management Practices relating to environmental protection, safety, and the suitability and healthfulness of the working environment.

The Heavy Element Facility's Facility Manager is responsible for the day to day management of the B251 facility, operations and staff, and for planning, documenting and authorizing activities, including those related to the NESHAPs air effluent monitoring program. The facility manager authorizes personnel access to B251.

ES\&H Team 3 provides subject matter expertise to the Heavy Element Facility management with respect to health physics, fire protection, criticality safety, industrial safety, industrial hygiene, and environmental protection. Specific responsibilities of the Team are delineated in LLNL (2000i) and in the discipline action plans for the facility.

\subsubsection{Building 331 - Tritium Facility}

The Superblock Manager is responsible to the AD of the Defense and Nuclear Technologies Directorate for ensuring that the Tritium Facility meets the Laboratory ES\&H requirements (Superblock is a complex comprised of the 330 block of buildings). The Superblock Manager appoints the Tritium Facility Manager and holds him/her responsible for assuring the safe and efficient day to day operation of the facility (LLNL, 1997d)

Specific responsibilities of the Tritium Facility Manager relevant to the NESHAPs air effluent monitoring program are to take all actions to keep the release of radioactive materials from normal operations and the consequences from accidents, incidents, and abnormal occurrences as low as reasonably achievable. A comprehensive list of all of the responsibilities of the Tritium Facility Manager, as well as those of the personnel who provide technical support to him/her are given in the FSP for the Tritium Facility (LLNL, 1997d).

ES\&H Team 1 provides support to the Tritium Facility with respect to programmatic safety and environmental issues (LLNL, 1999c). Specific 
responsibilities of the Team are given in LLNL (1997d) and in the discipline action plans for the Tritium Facility.

\subsubsection{Building 332 - Plutonium Facility}

As part of the Superblock complex, the Plutonium Facility is managed by the Superblock Manager, who is directly responsible to the AD for the Defense and Nuclear Technologies Directorate. The Superblock Manager appoints the Plutonium Facility Manager, to whom he/she has delegated authority for the day-to-day operations of the Plutonium Facility. The Superblock Manager has delegated to the Facility Manager the responsibility for operating and maintaining the facility and for ensuring that the facility meets Laboratory environmental, safety, and health requirements. The Facility Manager issues the FSP (LLNL, 1998a) which establishes the basic ES\&H controls for the facility and describes procedures for their implementation. In addition, various programmatic and support organizations perform work in the facility. Supervisors of these organizations are responsible for implementing the ES\&H controls specified by the FSP (LLNL, 1998a).

Specific responsibilities of the Facility Manager relevant to the NESHAPs air effluent monitoring program are to take all actions to keep the generation of radioactive wastes; release of radioactive materials from normal operations; and consequences from accidents, incidents, and abnormal occurrences as low as reasonably achievable. The FSP provides considerable detail on the ES\&H responsibilities of Facility staff, including those of the Facility Safety Officer, Facility Engineer; Electronic Engineering Representative, Health Physicist; Facility Training Officer, and Quality Assurance Engineer. Information on the specific responsibilities of each of these individuals is given in Chapter 3 of the FSP (LLNL, 1998a).

ES\&H Team 1 provides support to the Plutonium Facility (LLNL, 1998a, 1999d). The discipline action plans for the Plutonium Facility provide details of the Team's responsibilities.

\subsection{Response to Releases from Unplanned Operations}

This section documents the requirements of paragraph 4.240 CFR 61, Subpart $\mathrm{H}$ by describing the administrative controls at LLNL that ensure prompt responses in the event that radionuclide emission levels increase due to unplanned operations. Unplanned increases in radionuclide emissions can range in severity from minor transient increases to major release events. LLNL's emergency response system was developed to keep minor nonemergency incidents from escalating to major events, as well as to respond to major emergencies. That system and the supporting documentation are described here. 


\subsection{Emergency Response at LLNL}

Lawrence Livermore National Laboratory's policy is to develop and maintain a comprehensive emergency management system that is capable of responding to and mitigating the consequences resulting from on-site and significant nearby emergencies that could threaten Laboratory workers, the public, national security, or the environment. This emergency management system was developed to meet requirements delineated by Federal regulations and US DOE Orders, and is described in Emergency Plan 1993 (EP) (Sharry et al., 1997). This plan fulfills the requirements of federal regulations including 40 CFR 355 (Federal Register, 1987), SARA Title III Emergency Planning and Notification; 40 CFR 265 (Federal Register, 1980), 40 CFR 302.6 (Federal Register, 1985), and 29 CFR 1910.120 (Federal Register, 1996). The plan also meets the requirements of US DOE Order 151.1, Comprehensive Emergency Management System (US DOE, 1995b), and incorporates requirements from other DOE Orders and associated management guides. These other regulatory requirements include those set forth in DOE Orders 232.1A, Occurrence Reporting and Processing of Operations Information (US DOE, 1997); 5530.3, Radiological Assistance Program (US DOE, 1992a); 5530.5, Federal Radiological Monitoring and Assessment Center (US DOE, 1992b); 5530.1A, Accident Response Group (US DOE, 1991); and 5610.14, Transportation Safeguards System Program Operations (US DOE, 1993b). Furthermore, the federal government has established the Federal Radiological Emergency Response Plan (50 CFR 46) under the management of the Federal Emergency Management Agency (FEMA) for responding to incidents involving radiological materials (Federal Register, 1998).

The EP (Sharry et al., 1997) is a comprehensive emergency management plan that was designed to provide both technical and administrative response capabilities in the event of an operational emergency such as unplanned emissions of radionuclides. The EP is a formal agreement between the Laboratory, the Oakland Operations Office of DOE, and the cognizant DOE Program Secretarial Officer concerning on-site and nearby emergency preparedness activities and responsibilities for a range of credible emergencies at or near LLNL. The EP describes the Laboratory's comprehensive Emergency Management Program for response, mitigation, and 
associated maintenance activities at LLNL. The Laboratory organization specifically responsible for the initial and ongoing response to, and mitigation of, all operational emergencies at LLNL is the Onsite Emergency Response Organization (OERO). The members of the OERO meet, and the OERO becomes operational, under the direction of the on-duty Laboratory Emergency Duty Officer (LEDO), a senior management representative who is always on call. The OERO is headed by the Emergency Management Team (EMT) led by an emergency manager, and includes a deputy emergency manager, as well as emergency response and support management representatives from the following departments: Environmental Protection, Hazards Control, Health Services, Engineering, Public Affairs, Safeguards and Security, and Site 300. This team is supported by a staff and operates from the LLNL Emergency Management Center. All additional Laboratory resources respond to incidents at the direction of this team.

The EP also requires facilities at LLNL to develop plans to control facility-specific emergencies. Formal planning for emergencies at facilities that handle radionuclides is based on Facility Hazards Analyses documents and Safety Analysis Reports that are prepared within each directorate. These analyses provide the basis for developing emergency plans and include event scenarios, identification of event indicators, event consequences, emergency planning zones, emergency action levels, and response actions. In addition, FSPs and other emergency planning documents, developed for each building and/or facility complex, contain emergency response plans and procedures specific to a particular facility. The information contained in these documents is summarized below for each facility that has continuous air effluent monitoring.

Information in the EP (Sharry et al., 1997) is supplemented by Volume II, Part 10, of LLNL's ES\&H Manual (LLNL, 2000j). This document provides explicit details and procedures of operations to be followed in an emergency, as well as responsibilities of key emergency personnel. These key personnel include the first responder/Incident Commander (typically, the LLNL Fire Department), the Laboratory Emergency Duty Officer, and members of the appropriate ES\&H Team. These individuals are responsible for working collaboratively to develop an Incident Action Plan to control an emergency. This plan identifies health and safety requirements, strategic goals, and tactical objectives required to protect life, the environment, and property in the event of an emergency. Implementation of the Incident Action Plan is typically the responsibility of a member of the responsible ES\&H Team.

\subsubsection{EPD Emergency Response Program}

EPD is one of the Laboratory's important resources during certain emergencies and follows established LLNL reporting and dispatching protocols used for all emergencies. In the event of a large emergency requiring the involvement of EPD, it will support LLNL emergency response efforts by sending a senior member of EPD management to serve as an EMT 
member at the Emergency Management Center (EMC). For smaller scale incidents, an EPD Environmental Duty Officer (EPD-EDO), on call 24 hours-aday to support environmental emergency response needs, may report directly to the scene of an emergency.

EPD provides necessary expertise and equipment to ensure that releases of radiological materials are assessed for possible environmental impacts. EPD is also responsible for identification and implementation of environmental mitigation and corrective actions, containment, clean-up, disposal, environmental monitoring and modeling, notification of regulatory agencies, and preparation of required reports.

These operations for large-scale emergency incidents are conducted by EPD from the EPD Satellite Operations Center (EPD-SOC), according to the Environmental Satellite Operations Center Operations Manual (LLNL, 1998b) in conjunction with the LLNL EMT. For smaller incidents, EPD operations can be directed by the EPD-EDO or by the ORAD Environmental Analyst (EA) in the field.

The EPD-SOC may be activated at the request of the Incident Commander, the EPD-EDO, the EPD head, or the LEDO. It is activated according to prescribed procedures (Sharry et al., 1997) and normally is established in Room 1145 (Discovery Room) in Trailer 5475. The EPD-SOC is staffed by members of the ORAD and Hazardous Waste Management (HWM) Divisions.

The Environmental Operations Group (EOG) of ORAD is the primary EPD environmental support group for all LLNL programs and departments, and is usually involved in emergency response activities. Normally, Analysts from this group serve as members of ES\&H Teams that support groups of Laboratory programs. During an emergency that occurs during normal working hours, these analysts usually report to the scene of the incident to help identify the character of released material, the exact source of released material, the amount of released material, and the extent of the release. They also assess the threat to the environment, report to regulatory agencies if required, and direct actions to clean up spills if necessary. During off-hours, these responsibilities are usually performed by the EPD-EDO.

The TAMM Group of ORAD provides air and terrestrial monitoring and modeling support for all LLNL programs and departments. In an emergency involving the release of radioactive materials to the atmosphere or ground, TAMM may also provide backup environmental monitoring and modeling as requested. TAMM personnel are ready to respond to emergencies at all times during normal working hours and are "on-call" at other times. TAMM's response to an emergency may include determining the nature of radioactive material releases to the air for environmental purposes, determining the nature and extent of contamination, and evaluating the hazard to the environment and to the human populations outside of LLNL.

The Water Guidance and Monitoring Group (WGMG) of ORAD provides water monitoring and regulatory support for all LLNL programs and 
departments. In emergency situations, WGMG provides backup monitoring and regulatory agency coordination support for liquid spills or releases of hazardous or radioactive materials to the sanitary sewer, storm drains, the soil, and paved surfaces.

Both TAMM and WGMG follow the established LLNL reporting and dispatching protocols used for all emergencies. Emergency response sampling procedures generally follow those established for environmental surveillance monitoring but may be adjusted to the nature of the emergency.

The Permits and Regulatory Affairs Group (PRAG) of ORAD provides the hazardous waste and air permitting support functions for EPD. In an emergency, PRAG members are responsible for assessing regulatory compliance implications and for establishing contact with pertinent regulatory agencies.

The Technical Support Group (TSG) of ORAD provides technologists and equipment to support the monitoring activities of TAMM and WGMG. This group is activated by a request from either TAMM or WGMG. HWM provides coordination, equipment, and personnel for containment and clean-up of emergencies involving spills. It is also responsible for obtaining analytical laboratory support for clean-up operations.

\subsection{Emergency Response Plans for Monitored Facilities}

All facilities at LLNL have emergency response plans that are documented in Facility Safety Plans, as well as in supplemental reports as appropriate. Sections 3.2.1 through 3.2.6 lists these materials for each of the facilities monitored under the NESHAPs Program.

\subsubsection{Buildings 175, 177, and 491- AVLIS Facilities}

Emergency response procedures for the to be followed in the event of an accident or other emergency are described in the Shutdown, Surveillance, and Maintenance Plan for AVLIS Facilities (LLNL, 1999a). Additional details are also available in specific Facility Safety Plans (LLNL, 1997a,b).

\subsubsection{Building 251- Heavy Element Facility}

Emergency response procedures and policies for Building 251 are contained in the building FSP (LLNL, 1997c).

All radioactive materials handling spaces in the facility have monitoring systems that sample continuously for airborne contamination.

Building 251 is connected to the LLNL Emergency Dispatch Center from which critical safety information is broadcast over the building paging system for fire, evacuation, or any other emergency 


\subsubsection{Building 331 - Tritium Facility}

The FSP for the Tritium Facility (LLNL, 1997d) and the Building 331 Self-Help Plan (LLNL, 1997e) describe the procedures to be followed at the Tritium Facility in the event of an accident or emergency. Radioactive releases are generally handled by facility personnel rather than by emergency response teams outside of the facility. Radioactive release scenarios in Building 331 have been divided into several categories for purposes of employee response, and are based on the relative radiation hazards to individuals. These categories and their respective response procedures are described in the Building 331 Self-Help Plan (LLNL, 1997e).

Rooms in which tritium is handled are equipped with alarms that are triggered when the tritium concentration in room air is greater than 50 $\mu \mathrm{Ci} / \mathrm{m}^{3}$ (low-level alarm) or greater than $2000 \mu \mathrm{Ci} / \mathrm{m}^{3}$ (high-level alarm). Low-level room alarms are not considered an emergency and are responded to by facility personnel by procedures described in the Building 331 Tritium Monitor Alarms Manual (LLNL, 1997f). A high-level room alarm triggers a remote alarm in the Emergency Dispatch Center in the Fire Station, and a dispatcher notifies the designated ES\&H Team representative. Emergency response teams are not sent to the Facility unless specifically requested.

All air effluent from the facility is exhausted through one of two stacks; each stack is monitored for tritium release by both a continuous monitoring alarm system and continuous molecular sieve samplers. The alarmed samplers provide real-time total tritium concentration release levels. A low-level integrating stack alarm is triggered when the total tritium released to the environment exceeds $90 \mathrm{Ci}$ in fifteen minutes, or when the instantaneous tritium concentration in the stack exceeds $1 \mathrm{Ci} / \mathrm{m}^{3}$ (LLNL, 1997d,e). The emergency response procedures specified for a low-level stack alarm are identical to those for a high-level room alarm given above. Highlevel integrated stack alarms for Building 331 are automatically triggered in the event of a tritium release to the environment in excess of $900 \mathrm{Ci}$ in 15 minutes, or when there is an instantaneous stack concentration of $10 \mathrm{Ci} / \mathrm{m}^{3}$. Audible and visual alarms are triggered within the Tritium Facility as well as at the Emergency Dispatch Center; response procedures are delineated in LLNL (1997d,e).

\subsubsection{Building 332 - Plutonium Facility}

In the event of an unplanned release of radionuclides, or other accident or emergency at Building 332, facility personnel follow procedures and responsibilities described in the facilities safety plan document for the complex (LLNL, 1998a). The specific response procedures depend on the nature and magnitude of the event, which, in the case of a radionuclide release above a given threshold, is detected and indicated by alarm-equipped monitors. 
Air effluent from the facility is monitored at 11 discharge points, including both building and glove box exhaust systems. These discharge points are monitored by alarmed Eberline continuous air monitors (CAMs), and are also sampled by 16 filter-type aerosol collection systems. The latter are also continuous collection systems, but are not connected to an alarm. When the amount of alpha activity on the CAM filter reaches $25 \mathrm{cpm}$ above background, the CAM activates both a local visual and audible alarm, and triggers remote alarm on the alarm panel in the Building Coordinator's office and at the LLNL Emergency Dispatch Center. Each CAM is equipped with a detector-failure alarm; the signal is received at the alarm panel in the Building Coordinator's office. The entire alarm signaling process is checked quarterly by the HCD and the Plant Engineering Alarms Crew (LLNL, 1998a).

Personnel who work in the facility are required to take training courses to recognize the CAM alarms (as well as alarms for fire, security, and criticality), and to respond in the manner specified in the FSP (LLNL, 1998a).

\subsection{Notification Levels}

For the non-alarmed continuous air effluent monitoring systems in place at Buildings 175, 177, the unhardened portion of Building 251, and Building 491, detection of an unplanned release of radionuclides would occur subsequent to the regular collection and analysis of the passive filter samplers. The Health Physicist for the facility is notified immediately by the RML when gross alpha activity on a filter exceeds $3.7 \times 10^{-3} \mathrm{~Bq} / \mathrm{m}^{3}\left(1 \times 10^{-13}\right.$ $\mu \mathrm{Ci} / \mathrm{mL})$ or the gross beta activity exceeds $3.7 \times 10^{-1} \mathrm{~Bq} / \mathrm{m}^{3}\left(1 \times 10^{-11} \mu \mathrm{Ci} / \mathrm{mL}\right)$ (Tate et al., 1999). In the event of a spill or other release of radionuclides in Building 332 that is not sufficient to trigger a CAM alarm, these same notification levels also apply. Similarly, with respect to a spill or release in the Tritium Facility below levels that would trigger room or stack alarms, detection would occur following the weekly collection and analysis of molecular sieve samplers. The Facility Health Physicist would receive notification if the molecular sieves indicate a stack effluent tritium activity exceeding $3.7 \times 10^{4} \mathrm{~Bq} / \mathrm{m}^{3}\left(1 \times 10^{-6} \mu \mathrm{Ci} / \mathrm{mL}\right)$.

For LLNL facilities monitored by air filters, the TAMM Group of EPD has established a notification level of $3.7 \times 10^{-1} \mathrm{~Bq} / \mathrm{m}^{3}\left(1 \times 10^{-11} \mathrm{\mu Ci} / \mathrm{mL}\right)$ for gross alpha and gross beta activity concentration. The TAMM Group notification level for tritium emissions from Building 331 is $3.7 \times 10^{5} \mathrm{~Bq} / \mathrm{m}^{3}$ $\left(1 \times 10^{-5} \mu \mathrm{Ci} / \mathrm{mL}\right)$. Each of these notification levels is based on a dose to a member of the public receiving $1 \mathrm{mrem} / \mathrm{y}$, or $10 \%$ of the NESHAPs regulatory standard. These notification levels assume that the releases occur continuously throughout the year and that exposure occurs at a location corresponding to that of the SW-MEI. For air filter samples or molecular sieve samplers having confirmed results greater than these concentrations, EPD and the facility management are notified. 


\subsection{Air Effluent Sampling Locations}

This section addresses the requirements of paragraphs 4.3 and 4.3 .1 of Appendix B, 40 CFR 61 Subpart H. Those paragraphs stipulate that the QAPP include a description of the sample collection and analysis procedures used to measure radionuclide air effluent, as well as identification of the sampling sites, the basis of sample site selection, and a list of the number of sampling points.

\subsection{Sampling Locations}

At any given time, LLNL maintains and operates approximately 76 continuous air effluent sampling systems for the measurement of radiological activity concentrations at discharge points to the atmosphere. Table 1 lists the 6 facilities at the Livermore site having continuous sampling systems, along with the analytes of interest, the type of sampler, and number of samplers. The majority of systems sample for radioactivity in the form of particles or aerosols at facilities having operations with the potential to release uranium, transuranics, and/or fission products. These samples are analyzed for gross alpha and gross beta activities. Air effluent sampling for tritium is conducted at one facility. In addition to samplers whose results are used for environmental reporting, Buildings 331 and 332 also have continuous air monitors with alarm capabilities to provide immediate warning in event of a significant release of radioactivity to the atmosphere. (These alarm-equipped monitors are for safety purposes and are not maintained as part of the NESHAPs program.)

\subsection{Site Selection}

The rationale for air sampling site selection is based on two criteria (1) are sampling systems required by NESHAPs, and (2) are sampling systems consistent with the DOE ALARA (as low as reasonably achievable) policy. Historically, monitoring of radionuclide air effluents at LLNL has been implemented according to the ALARA policy. That policy is meant to ensure that DOE facilities have capabilities, consistent with their operations, to monitor routine and non-routine radiological releases, so that the radiological dose to the public can be assessed and that doses themselves are ALARA. Since the ALARA policy and LLNL facilities predate the National Emission Standards for Hazardous Air Pollutants (NESHAPs) 40 CFR 61, Subpart H regulations promulgated in 1991, nearly all of the continuous sampling systems were placed into operation as a result of the ALARA philosophy. The systems were installed by each facility in conjunction with the HCD. The rationale for installation was not only for the demonstration of ALARA dose to the public from routine emissions, but also to have an accurate source term in the event of accidental or abnormal releases, to 
confirm environmental surveillance measurements, and to provide ongoing corroboration that emissions control systems are working properly.

With the promulgation of Subpart $\mathrm{H}$, continuous sampling of a discharge point is required if the potential off-site EDE to any individual is greater than $0.1 \mathrm{mrem} / \mathrm{y}$, as calculated using the EPA-mandated air dispersion-dose model and assuming no emission control devices [Subpart $\mathrm{H}$ 61.93 (b)(4)(ii)]. Determination of this requirement is usually made by a NESHAPs evaluation of operations prior to start up, or when there is a planned change in operations, which results in the potential for increased radiological discharges to the atmosphere. The evaluation consists of an estimation of emissions by either measurement of unabated emissions or by

Table 1. LLNL Radiological Continuous Sampling Systems

\section{Building}

Facility

\section{Analytes}

Sample type

Number of samplers

175

AVLIS

Gross $\alpha, \beta$ on particles

Filters

177

AVLIS

Gross $\alpha, \beta$ on particles

Filter

251

Heavy Elements

Unhardened area 
Gross $\alpha, \beta$ on particles

Filters

Hardened area

Gross $\alpha, \beta$ on particles

Filters

331

Tritium

Tritium

Ionization Chamber ${ }^{\mathrm{a}}$

Gaseous tritium/tritiated water vapor

Molecular sieves

332

Plutonium

Gross $\alpha, \beta$ on particles

CAM $^{\mathrm{a}}$

Gross $\alpha, \beta$ on particles

Filters

491

AVLIS

Gross $\alpha, \beta$ on particles

Filters 
a Alarmed systems.

Note: "CAM" denotes Eberline continuous air monitors.

an inventory approach, followed by modeling using the CAP88-PC code to find the dose to the MEI. In cases where the radiological usage inventory is used as the source term for estimation, potential emissions are predicted by applying a physical state factor to the radiological inventory as described in Method D of 40 CFR 61, and by assuming normal operations, but without reduction for any pollution control devices.

\subsubsection{Operations With Continuous Monitoring}

Sampling systems required by NESHAPs include all systems at discharge points where a NESHAPs evaluation has been performed and the estimated unabated EDE result is greater than $0.1 \mathrm{mrem} / \mathrm{y}$, or where LLNL agrees to maintain continuous sampling of exhausts in lieu of a NESHAPs evaluation. The sampling in the Building 251 seismically-hardened area and Buildings 331 and 332 are in lieu of a NESHAPs evaluation. Exhausts with sampling systems in the hardened area of Building 251 and 332 include those from glove box operations where radiological materials are handled, and also those from room areas. Since no emissions would be expected from room exhausts under normal operating conditions, sampling of these exhausts is not strictly required under NESHAPs. Nevertheless, sampling of the room exhausts at these facilities continues as a best management practice.

The remainder and majority of the continuous sampling systems are not required as a result of NESHAPs evaluations. These include continuous sampling systems in Buildings 175, 491, and the unhardened area of 251. Sampling in Building 177 had been required until the recent shutdown of the AVLIS program; sampling continues in this building during operations to prepare the building for transfer to another LLNL program. With respect to Building 251 (unhardened area), the only operations currently conducted are those pertaining to the storage and transfer of radioactive materials; clean-up; and waste processing and removal from the building. As discussed above, the evaluations conducted to assess dose to the MEI are based on emissions estimated by the inventory approach or by actual sampling results of the unabated air effluents. Resulting doses to the MEI evaluated for each of these individual discharge points are less than the $0.1 \mathrm{mrem} / \mathrm{y}$ criterion for continuous sampling. Even though not required by NESHAPs, the sampling at these discharge points continues both as a best management practice, and for reasons cited in the ALARA discussion above. Sampling for the potential release of particulate radiological emissions at the other facilities in this group also continues. For annual reporting purposes, emission estimates for each monitored discharge point are based on actual sample results. Corresponding 
doses are included in the dose to the site-wide maximally exposed individual for the Livermore site for the year.

\subsubsection{Other Operations}

Discharges from existing operations that have a potential to release radionuclides but that are either unmonitored or are not continuously monitored, are assessed annually to determine compliance with NESHAPs. This compliance assessment process identifies both air emission points and diffuse sources at LLNL that have the potential to discharge radionuclides to the atmosphere. Radionuclide usage inventory data are collected on each potential source, and used to develop a source term to estimate releases. A full $(100 \%)$ inventory i.e., of all LLNL Facilities, is conducted every three years; only the "key" Livermore site facilities, defined as those in a ranked list that collectively accounted for $90 \%$ (or greater) of the previous year's Livermore site radiologic dose to members of the public, are reinventoried annually (LLNL, 1998c; 2000b). These evaluations are performed by the TAMM Group in EPD. To update radionuclide usage inventories and operations, as well as stack information, inventory forms and appropriate guidance are sent to Livermore site facilities and Site 300. These forms are completed by experimenters, certified by facility managers, and returned to EPD for dispersion and dose assessment modeling. The potential EDEs to members of the public are calculated, and indicate if any additional discharge points need monitoring. Results of these evaluations, the estimated emissions, and doses to the public, are reported annually in the LLNL NESHAPs report e.g., Gallegos et al. (1998).

In addition to the annual assessment process, EPD is notified when new or modified operations or facilities are planned. EST's provide a formal communication forum within EPD on programmatic issues related to compliance with environmental regulations (see Section 2.3.3). Currently, the Environmental Evaluations Group of EPD, which conducts reviews for compliance with the National Environmental Policy Act, notifies the TAMM Group of proposed new or modified operations. If the proposed facility or project includes operations that have a potential for radiological releases to air, a NESHAPs compliance assessment is performed. That assessment is performed to ascertain (1) whether an application to construct or modify is required; and (2) to determine if continuous monitoring is required. Both components of the compliance assessment are based on the inventory approach described above, and entail calculating an effective radiological emission rate by applying EPA-specified fractions for potential release to air of materials in different physical states (solid, liquid, powder, gas) for each radioisotope. The inventory quantity (in curies) is multiplied by a statedependent release fraction to give the potential annual release to air i.e., the "effective" emission rate, in accordance with 40 CFR 61, Appendix D. An application to construct or modify is required if the estimated abated emissions result in a calculated dose greater than $0.1 \mathrm{mrem} / \mathrm{y}$, whereas 
continuous monitoring is required if the unabated emissions yield a potential dose greater than $0.1 \mathrm{mrem} / \mathrm{y}$.

LLNL also conducts periodic confirmatory sampling at selected discharge points in accordance with Subpart H 61.93 (b)(4)(i) to verify that potential emissions are acceptably low or zero, and to demonstrate that the radiological usage inventory process results in conservative estimates of dose. Previous confirmatory sampling efforts of operations have always validated that continuous sampling at the selected discharge points is not required.

The procurement of any goods or services purchased to address requirements of the NESHAPs program are controlled by institutional policies described in the University of California's Laboratory Procurement Policy and Standards Practices Manual (University of California, 1998). 


\subsection{Description of Sampling Probes and Representativeness of the Samples}

In this section we discuss elements of the radiological air effluent sampling systems that may affect the representativeness of sampling, as required by paragraph 4.3.2 of Appendix B, 40 CFR 61 Subpart H. Those elements addressed here include the extraction probe design, sampling location and probe placement, sample transport line, aerosol distribution, sample collector, and the degree of isokinetic sampling.

The air effluent sampling locations meet the requirements of 40 CFR 60, Appendix A, Reference Method 1 as called for by Subpart H (b)(2)(i) for particle sampling traverses. Because LLNL facilities were in place before the NESHAPs regulations became effective, the requirement for a minimum of 8 duct diameters downstream and two duct diameters upstream from any flow disturbance is not usually feasible to attain. The alternative requirement of 2 duct-diameters downstream and one-half diameter upstream from any disturbance, as allowed in Method 1 section 2.1, is met for sampling systems required by NESHAPs, i.e., those in the Building 251 hardened area, Building 331, and Building 332. For the sampling systems in place before the NESHAPs regulations and not required by NESHAPs, sampling locations may not necessarily meet the location requirements. Where feasible, sampling locations are near the discharge point to the atmosphere. And, at facilities having emission control devices, sampling takes place after air passes these devices.

To achieve representative samples, a volume of air is continuously removed from the air effluent discharge duct using an extraction probe. Potential contamination issues preclude the use of in-line air samplers. For those exhaust points where continuous sampling for aerosols is required, sample extraction probes have been designed, fabricated and installed to meet the American National Standards Institute (ANSI) guidelines (ANSI, 1969) called for by Subpart H (b)(ii)(2). The extraction probes are sometimes multinozzled i.e., air is withdrawn through nozzles at more than one point across the exhaust duct and joined into a collection manifold. For circular ducts, nozzles are located in equal concentric annular areas as per the guidelines. For rectangular ducts more than a single multi-nozzle probe is used to provide adequate sampling coverage across the cross section of the duct. The extraction at multiple points helps insure that representative sampling is attained even if particles are not evenly distributed across the cross section of the duct. For smaller ducts (less than 8 inches in diameter), only a single nozzle extraction probe is used. Extraction probes having multiple nozzle inlets are in place for the Building 491 sampling system. Probes are positioned isoaxially in the exhaust duct and the sample nozzles have tapered edges. Probes and nozzles are made of stainless steel so that no degradation is expected to occur under normal facility operations. Sampling is performed at 
temperature and humidity conditions similar to that in the facility to insure representativeness of the sample.

The extracted air passes though a sample transport line, and is delivered to the air samplers. In the particle sampling systems, particles in the extracted air are collected on 47-mm diameter membrane filters. Where feasible, the filter collectors are connected to the extraction probe immediately outside the duct to minimize the length of the sample transport line, and therefore, minimize particle loss in the transport line. Bends are also avoided or minimized because of associated particle losses in the transport line. Where bends cannot be avoided, they are made gradually to minimize particle deposition. Sampling lines are constructed from materials that are resistant to degradation by constituents in the sampled air. The membrane filters are at least $98 \%$ efficient (Hoover and Newton, 1991) for the collection of particles at the sample flow rates used. For tritium sampling, tritium gas and tritiated water vapor are collected in molecular sieves (Ostlund and Mason, 1974).

The ANSI guidelines for sampling radioactive aerosols also require that sampling be isokinetic. Isokinetic sampling occurs when the sampler flow rate and extraction nozzle size are such that the velocity through the inlet nozzle is equivalent to the gas velocity in the duct being sampled. This insures that a representative size distribution of the aerosol is being sampled. For the locations required to have continuous sampling, sample flow rate and extraction probe inlet nozzles have been designed to operate in a range from less than isokinetic to $100 \%$ isokinetic sampling. Less than isokinetic sampling guarantees that sampling is conservative in the case where the aerosol distribution being sampled contains particles micron-sized or greater. LLNL has previously provided notice of our intent to conduct less than isokinetic sampling in a request from US EPA Region IX to provide additional data on our sampling systems. With the submittal of this additional information including the rationale for less than isokinetic sampling, US EPA Region IX approved our compliance with Subpart H in a 1994 memorandum (US EPA, 1994b).

For the representative sampling of aerosols, it is also relevant to consider the size distribution of the aerosol being sampled. At LLNL, the sampling sites for particles are located after at least one stage of high efficiency particulate air (HEPA) filtration. HEPA filters are rated as $99.97 \%$ efficient for $0.3 \mu \mathrm{m}$ diameter particles [American Society of Mechanical Engineers (ASME) 1989] and they are even more efficient for larger particles (Biermann and Bergman, 1988). Thus, the majority of particles penetrating such filters are submicron in size. Such small particles are able to follow the flow stream lines of the gas and are much less apt to become non-uniform in concentration or size distribution over the cross section of the duct than are micron-size and larger particles. They are also far less susceptible to appreciable deposition in sampling transport lines and losses due to anisokinetic sampling. Therefore, the size distribution of the aerosols being 
sampled is conducive to representative sampling. Information on the testing of HEPA filters used at LLNL is provided in the next section.

\subsection{Continuous Air Monitoring and Sampling Systems}

The continuous air monitoring and sampling systems used to characterize and measure radionuclide releases from facilities at LLNL are described in this section. Information is also provided on the frequency of sample collection, calibration procedures, frequency of calibration, and detection sensitivity as called for in paragraphs 4.3.3 and 4.3.4 of Appendix B, 40 CFR 61 Subpart H.

\subsection{Sampling System Types}

Facilities at LLNL that are continuously monitored for radionuclide discharges to the atmosphere utilize alarm-equipped sampling systems for safety purposes and/or non-alarmed sample collection systems to characterize radionuclide effluent for compliance with NESHAPs. These systems, and the facilities that use each type, are described in the following sections.

\subsubsection{Alarm-Equipped Sampling Systems}

At LLNL, two discrete types of alarm-equipped systems provide immediate detection of elevated levels of radionuclides exhausted from facility stacks; these are continuous air monitors (CAMs), used for the detection of alpha activity in the form of aerosols, and ion chambers, used for the detection of tritium concentrations in air.

\subsubsection{Continuous Air Monitors (CAMs)}

Stack CAMs used to monitor radionuclide effluent are Eberline model Alpha 5A. These units provide immediate (real-time) measurements of alpha activity in stack effluent air. Each unit has both an audible and visual alarm, and is provided with emergency power. Each CAM has a solid state detector, flow and rate meters, a strip-chart recorder, and an internally mounted 47-mm-diameter filter to collect particles from the air. A singlechannel pulse height analyzer detects a specific-energy range of alpha activity; thus, much of the activity from radon/thoron can be subtracted, resulting in increased detection sensitivity for radionuclides having alpha energies within this range.

Stack CAMs (sampling after HEPA filters) are currently installed only in Building 332. Technologists remove and replace the filter of each stack CAM weekly in accordance with Health Physics Discipline Action Plan Instruction (DAP) HP-18-W (LLNL, 1999d). A logbook is kept for each CAM at its location; at the time of filter exchange, the technologist records the background reading on the CAM rate meter; the flow rate; the plutonium 
check source activity, and the count rate shown on the meter. The technologist also source-checks the CAM to ensure that an alarm is triggered when the set-point is reached; calculates and records the CAM efficiency; replaces the CAM if the efficiency is less than $10 \%$; places a new filter in the CAM; and checks and replaces the chart paper as required (LLNL, 1999d).

Subsequent to collection, CAM filters are tagged with a unique bar code and logged into the HCD Sample Tracking and Receiving (STAR) computer system prior to submittal to the RML for analysis (HCD, 1995a). Analytical results for each sample filter are provided to the facility Health Physicist and to TAMM. During 1999, the range of the minimum detectable concentration (MDC) of gross alpha activity on CAMs in B332 was $2.5 \times 10^{-15}$ to $4.0 \times 10^{-15}$ $\mu \mathrm{Ci} / \mathrm{mL}$. The corresponding MDC for gross beta activity was $4.6 \times 10^{-15}$ to 7.3 $\times 10^{-15} \mu \mathrm{Ci} / \mathrm{mL}$.

Stack CAM flow rate and radiation detectors are calibrated annually by the Calibration and Standards Laboratory (CSL) of the HCD. Calibration procedures are documented and performed with sources traceable to the National Institute for Standards and Technology (NIST) (CSL, 1996).

\subsubsection{Ion Chambers}

Air effluent from the Tritium Facility is exhausted through two stacks, each of which is equipped with a continuous monitoring alarm. Each alarmequipped system consists of two Overhoff ion chambers in parallel, one of which monitors and detects high tritium concentrations (>900 Ci released within a 15 minute-period); one which monitors and detects low tritium concentrations (a low-level alarm is triggered when the total tritium released to the environment exceeds $90 \mathrm{Ci}$ in 15 minutes, or the tritium concentration in the stack exceeds $1 \mathrm{Ci} / \mathrm{m}^{3}$ ) (LLNL, 1997d).

Weekly operational checks of the Overhoff ion chamber monitors are performed by building alarms crew personnel according to DAP Instruction HP-14-W (LLNL, 1999c). The ion chambers and their alarms are also checked for proper operation every six months on the basis of the Stack Monitor Operational Test Procedure described in LLNL (1997f). These monitors are exchanged for newly calibrated monitors on an annual basis. Ion chamber calibrations are performed by alarms crew personnel using the Overhoff Room and Stack Monitor Calibration Procedure in LLNL (1997f). Monitors are examined visually, cleaned, and various function tests are performed. The display board, auto scaler board, high and low alarm points, and the electrometer are calibrated, with the results recorded manually in an equipment logbook; a sticker recording the date of calibration is placed on the unit (LLNL, 1997f). 


\subsubsection{Non-Alarmed Sampling Systems}

Non-alarmed radionuclide sample collection systems in building stacks are either filter-type continuous aerosol collectors or molecular sieves. These samplers are exchanged at specific intervals, and provide the primary data used to determine environmental releases of radionuclides. Molecular sieves are used solely at Building 331. Both types of monitoring systems are maintained in support of LLNL's NESHAPs program.

\subsubsection{Filter-Type Samplers}

Stack filter-type samplers collect particulate materials on 47-mmdiameter glass or cellulose fiber filters. Samplers are located adjacent to an extraction probe (see Section 5.0) and are designed and installed in accordance with 40 CFR 61 Subpart $\mathrm{H}$ and standards established by the American National Standards Institute (ANSI, 1969). The filters are collected weekly or bi-weekly by Health and Safety Technologists in accordance with Environmental Discipline Action Plans (LLNL, 1999e,f,g), logged into the HCD STAR system, and are submitted to the RML for analyses of gross alpha and gross beta activity (HCD, 1995a). Flow calibration of samplers is performed by Health and Safety Technologists annually (LLNL, 1999e,f,g).

The MDC of gross alpha and gross beta activity on each filter is determined by the RML at the time of filter analysis. These data are provided along with the analytical results to the TAMM group and to the facility Health Physicist. During 1999, the range of the MDC of gross alpha activity on filters was $1.2 \times 10^{-15}$ to $1.7 \times 10^{-14} \mu \mathrm{Ci} / \mathrm{mL}$. The corresponding MDC for gross beta activity was $2.1 \times 10^{-15}$ to $2.5 \times 10^{-14} \mathrm{\mu Ci} / \mathrm{mL}$.

\subsubsection{Molecular Sieves}

Samples of tritiated water vapor and tritiated hydrogen gas released from Building 331 are collected in continuously operated molecular sieves sampling each of the building's stacks. Each molecular sieve sampler (nonalarmed) is installed in parallel with alarm-equipped ion chambers (see Section 6.1.1.2). Each sieve sampler consists of two molecular sieve traps; tritium existing as water vapor (HTO) is absorbed by the first trap containing Linde Molecular Sieve Type 4A; tritiated molecular hydrogen (HT) passes through this sieve and into the second trap, which contains a molecular sieve coated with a finely dispersed palladium catalyst. This palladium catalyst converts tritiated molecular hydrogen to tritiated water vapor. The water analyzed from the first trap indicates the stack effluent concentration of HTO; water analyzed from the second trap yields the concentration of HT. These data, combined with measured values of stack effluent flow rates, yields the amounts of HT and HTO released. Actual gas flow through the sieves is 0.25 $\mathrm{L} / \mathrm{min}$. 
Molecular sieves are collected and analyzed weekly. The MDC of HT and HTO are determined by the RML for each sample at the time of analysis. As with the filter data, these results are provided, along with analytical results, to the TAMM Group and to the facility Health Physicist. During 1999, the MDC for HT and HTO in stack effluent concentrations ranged from $7.0 \times$ $10^{-11}$ to $1.9 \times 10^{-10} \mu \mathrm{Ci} / \mathrm{mL}$.

\subsection{Sampling Systems at Facilities}

This section describes the air effluent sampling systems in use at each of the continuously-monitored facilities at LLNL.

\subsubsection{Building 175 — AVLIS Program}

Air effluent exhausted from Building 175 is monitored for particles by six filter-type continuous samplers. Each of these samplers is located downstream of a single stage of HEPA filtration (Tate et al., 1999); sampler flow rates are $50 \mathrm{~L} / \mathrm{min}$. Filters are exchanged weekly, and analyzed for gross alpha and gross beta activity (LLNL, 1999g).

\subsubsection{Building 177 — AVLIS Program}

Gross alpha and gross beta emissions from Building 177 are monitored at a single location by a filter-type continuous sampler. This sampler is located downstream of HEPA-filtered glovebox operations and is exchanged and analyzed weekly (LLNL, 1999g). The sampler has a flow rate of $40 \mathrm{~L} / \mathrm{min}$.

\subsubsection{Building 251 - Heavy Element Facility}

Air effluent from the seismically-hardened portion of the Heavy Element Facility is monitored by four required continuous filter samplers. These samplers are located downstream of one to three stages of HEPA filtration (LLNL, 1999e; Tate et al., 1999).

The remainder of the facility, designated the unhardened area, has 28 filter-type continuous samplers. These filters continuously sample individual emission points from either glove boxes, fume hoods, or rooms. Sampler flow rates range from 7 to $34 \mathrm{~L} / \mathrm{min}$, depending on the rate of air exhausted from individual discharge points. Sampler filters are changed bi-weekly (LLNL, 1999e). 


\subsubsection{Building 331 - Tritium Facility}

Air effluent from the Tritium Facility is exhausted through two stacks, each of which is equipped with a continuous monitoring alarm system (ion chambers) and continuous molecular sieve samplers. These monitoring systems are described in Sections 6.1.1.2 and 6.1.2.1. The molecular sieve samplers are checked daily for flow rate and proper operation by a Health and Safety Technologist based on procedures given in ES\&H Field Support Instruction Env-3 (LLNL, 1999h). These samplers are exchanged weekly by a Health and Safety Technologist following procedures in ES\&H Field Support Instruction Env-4 (LLNL, 1999h). The sieve samplers are submitted to the AL for extraction of tritiated water (HCD, 1996c); this water is subsequently submitted to the RML for quantification of tritium activity by liquid scintillation counting (HCD, 1997). The RML also receives measured stack flow rate data, and uses these data to calculate stack effluent tritium concentrations.

\subsubsection{Building 332 - Plutonium Facility}

Stack monitoring at Building 332 is accomplished using CAMs and filter-type continuous samplers. These stack sampling devices measure radioactive materials released from building and glovebox ventilation systems, and are typically located downstream from one to three stages of HEPA filtration (LLNL, 1995a).

Each of the twelve stack CAMs used for effluent monitoring in Building 332 are Eberline model 5A alpha detectors. When the amount of alpha activity on a CAM filter reaches $25 \mathrm{cpm}$ above background, visual and audible alarms are activated. Each CAM is also equipped with a detectorfailure alarm (LLNL, 1999d).

Environmental sampling for radionuclide releases from Building 332 is accomplished with 16 filter-type continuous samplers. These samplers have stack-dependent flow rates ranging from $15-30 \mathrm{~L} / \mathrm{min}$. Filters are collected weekly by facility Health and Safety Technologists (LLNL, 1999d) and submitted to the RML for analysis.

\subsubsection{Building 491 — AVLIS Program}

Air exhausted from experimental or process areas of Building 491 is sampled for radionuclides by filter-type continuous samplers. There is one sampler at Building 491; the filter is exchanged weekly. That sampler has a flow rate of $55 \mathrm{~L} / \mathrm{min}$ (LLNL, 1999g). Effluent from the building passes through two stages of HEPA filtration prior to discharge (Tate et al., 1999). 


\subsection{High Efficiency Particulate Air (HEPA) Filtration}

As noted previously, HEPA filters are located upstream of samplers at all building stack discharge points with continuous sampling systems for aerosols. In general, HEPA filters are very effective for the removal of particles from the air. Although they are characterized as having high efficiencies for aerosols of all sizes, particles of 0.1 to $0.3 \mu \mathrm{m}$ diameter have the greatest penetrating potential. Removal of larger aerosols occurs by inertia and interception capture mechanisms, while removal of the smaller aerosols occurs by diffusion.

The HEPA filters used in all LLNL facilities are tested by a US DOE filter test facility prior to installation, and are certified to have a minimum particleremoval-efficiency of $99.97 \%$ for particles of $0.3 \mu \mathrm{m}$ diameter and larger (LLNL, 2000k). Once installed at LLNL, HEPA filters are tested annually for leakage and overall integrity by the Industrial Hygiene Instrument Laboratory (IHIL) of HCD based on standards developed by the American Society of Mechanical Engineers (ASME, 1989) and Burchsted et al. (1979). These standards include protocols for visual inspection, aerosol penetration, and seal integrity. Test results are recorded manually, then maintained in an electronic database that is backed up automatically on a daily basis. Written reports that summarize HEPA filter test results are furnished to the appropriate Industrial Hygienist and/or Health Physicist, with copies also provided to the building manager, ES\&H Team Leader, and others as requested. Specific test procedures, and details of written report contents are contained in Industrial Hygiene Instrument Laboratory Procedure No. HEPA 1.0 (Rev.4), 1996 (IHIL, 1996). Information concerning HEPA filter system design guidelines for LLNL are available in LLNL's ES\&H Manual Volume II Part 13 (LLNL, 2000k).

\subsection{Laboratory Analysis Procedures and Standards}

This section contains a description of the laboratory analysis procedures used to measure tritium collected from molecular sieves, and gross alpha and gross beta activity on filters. Information is also included on calibration procedures and the frequency of calibration, as required in paragraph 4.3 .5 of Appendix B, 40 CFR 61 Subpart H.

\subsection{Tritium Analysis}

Tritiated water collected by molecular sieves is recovered by first heating the molecular sieve traps under vacuum in a modified Thermolyne muffle furnace (Type 1700). The water vapor that evolves is collected in stainless steel cold traps, and the mass of the extracted water, molecular sieves, and cold traps are recorded. This procedure is conducted in the HCD 
AL according to protocols delineated in HCD (1996b). Once the extraction process is complete, samples are submitted to the HCD RML for analysis by liquid scintillation (LS) counting. The RML uses several different LS counters to quantify tritium in samples of water. The preferred analyzers are Beckman Counters models 5801 or 6500 (HCD, 1997). Each group of samples is analyzed along with an Instrument Auto Calibration Standard, three tritium commercial glass vial quench standards, a commercial glass vial background standard, a scintillation cocktail blank, a polyethylene vial tritium standard, and a polyethylene vial background standard. Each of the latter two standards are run in pairs; as a 'beginning-of-run' sample, and as an 'end-of-run' sample. Polyethylene vial tritium- and background-working standards are also included in each sample run (HCD, 1997). Calibration standards are traceable to the National Institute for Standards and Technology Laboratory (NIST). The LS counting methods conform to the requirements of 40 CFR 61 Appendix B, Method 3.3.3 for beta counting by scintillation counters. Specific procedures for LS counting are contained in HCD (1997).

\subsection{Gross Alpha and Gross Beta Analysis}

Filters collected from continuous samplers on facility air discharge points are analyzed using methods specified in 40 CFR 61, specifically 3.1.4Method A-4 for gross alpha determination, 3.3.2-Method B-4 for gross beta determination, and 3.5.1 for alpha counting using gas flow proportional counters. The RML holds filters four days after collection to allow for the decay of naturally-occurring radon daughters. Filters are counted on either a Tennelec model 5500 gas proportional detector with a fifty-sample capacity, or a Canberra model $2400 \mathrm{~F}$ with an 88 sample capacity. Each sample batch includes an alpha and a beta efficiency check source, plus an alpha standard $\left({ }^{238} \mathrm{Pu}\right)$ and beta standard $\left({ }^{90} \mathrm{Sr}\right)$. These calibration standards are NIST-traceable. Background samples are included in every tenth position of the counters (HCD, 1995a).

\subsection{Laboratory Waste Handling}

Sample preparation by the AL, and sample analyses by the RML result in small quantities of low-level radioactive waste. Handling and disposal of this waste is completed in accordance with DOE Order 5820.2A (US DOE, 1988a). LLNL has developed a comprehensive set of waste handling and waste disposal criteria and procedures to facilitate compliance with this order. These criteria and procedures are contained in the document Waste Acceptance Criteria (LLNL, 1996b). It is a policy of both the AL and the RML that all waste handling complies with applicable environmental, safety, and LLNL requirements (HCD, 1996a,b; LLNL, 20001). 


\subsection{Sample Flow Rate Measurement System, Calibration Procedures, and Frequency of Calibration}

To meet the requirements of paragraph 4.3.6 of Appendix B, 40 CFR 61 Subpart $\mathrm{H}$, this section provides information on sample flow rate measurement systems, calibration procedures, and the frequency of calibration. Both alarm-equipped (non-NESHAPs) and non-alarmed sampling systems (maintained in support of NESHAPs) in use at continuously-monitored facilities are discussed.

\subsection{Alarm-Equipped Sampling Systems}

Flow-rates of the alarm-equipped CAMs at Building 332 are specified in the "Air Sampling/Monitoring Documentation Form" of the Environmental Discipline Action Plan for this facility; flow rates are verified weekly (LLNL, 1999d). CAMs are calibrated annually by the Calibration and Standards Laboratory (CSL) of the HCD (CSL, 1996).

Weekly operational checks of the Building 331 alarm-equipped Overhoff ion chamber monitors for proper air flow, correct alarm set-points, and detector response are performed by the Building 331 Health and Safety Technologist according to specifications given in LLNL (1999c). These monitors are exchanged for newly calibrated monitors on an annual basis; ion chamber calibrations are conducted by alarms crew personnel using the Overhoff Room and Stack Monitor Calibration Procedure (LLNL, 1997f).

\subsection{Non-Alarmed Sampling Systems}

For the non-alarmed filter-type continuous samplers in place at Buildings 175, 177, 251, 332, and 491, Environmental Discipline Action Plans (LLNL, 1999e,f,g) require the annual calibration of stack sampler flow rate(s). Rotometers are used at Buildings 175, 177, and Building 332 to verify and/or adjust flow rate through the samplers. Building 491 has flow rate adjustments and flow controllers integral to the pump. Individual air pumps for sampling are in place at Buildings 177 and 491; systems at Buildings 175 and 332 rely on facility air-moving systems, where sampling systems are connected to a common pump. At Building 332, backup pumps are activated in the event of pump failure or inadequate system pressure.

The sampling systems at Building 251 utilize facility air-moving equipment, which have backup pumps in the event of pump failure and/or inadequate pressure. In the seismically-hardened area of Building 251, rotometers are used to verify and adjust sampler flow rates weekly; samplers in the unhardened area of Building 251 rely on critical orifices to maintain the flow rate.

The flow rates and other key operating parameters of the molecular sieve samplers at Building 331 are checked and adjusted daily as described in 
Environmental Safety and Health Field Support Instruction (LLNL, 1999h). The sampling systems at Building 331 are equipped with individual air pumps, and rotometers are used to verify and adjust the molecular sieve sampler flow rates.

\subsection{Effluent Flow Rate Measurement Procedures}

LLNL determines the air effluent flow rate from discharge points having continuous sampling systems. This section describes the procedures used in these measurements, in accordance with paragraph 4.3.7 of Appendix B, 40 CFR 61 Subpart H.

\subsection{Effluent Flow Rate Measurement}

The flow rate of air being discharged is calculated based on measurements of the duct area and of gas velocity in the exhaust duct. The flow rate from a discharge point, along with the concentration of radiological constituents in the discharge as determined by the continuous sampling systems, determines the total emissions for the discharge point for a year. The gas velocity measurements are also used to assess the degree of isokinetic sampling for particulate samplers, and to provide discharge velocity input for the CAP88-PC dispersion code used to model the dose to the public.

LLNL performs velocity traverse measurements periodically for all discharge points having continuous air samplers. Traverse measurements entail the measurement and recording of the gas velocity at prescribed points over the cross section of the air discharge duct so that a representative average velocity, and subsequent discharge flow rate, can be calculated.

The air velocity exiting a discharge point is determined by performing velocity traverse measurements as called for in "Determination of Stack Gas Velocity and Volumetric Flow Rate," 40 CFR 60, Appendix A, Method 2. The method specifies the use of a standard S-type pitot tube for the velocity measurement. The number of traverse points and the locations of velocity measurements are specified in "Sample and Velocity Traverses for Stationary Sources," Appendix A, Method 1. Where possible, the traverses are performed near the location of the continuous air samplers. Determination of the cross sectional area of the duct (to determine discharge flow rate) at the point of the traverses is made by physical measurement.

When the NESHAPs regulations were first promulgated, the S-type pitot tube device was used at all locations where feasible. For some stacks, the air velocity was so low that the pitot tube could not provide a reliable measurement. LLNL received approval (US EPA, 1993) to use thermal anemometer probes as an alternative method for velocity measurement (Federal Register, 1993b). The anemometer-type instrument allows the accurate measurement of lower velocities than is possible with the pitot tube. Also, the anemometer instrument is more conducive for field use; it is smaller, and is easily used by a single operator. In addition, the anemometer 
instrument has provisions to record measurements as they are taken, and is considered safer because it is less cumbersome. The use of anemometer probes has also been established as an alternative method in the DOE/EPA Memorandum of Understanding issued in 1995 (US DOE, 1995a). Anemometers, calibrated and re-certified annually by the manufacturer, are now used at all locations for the velocity traverse measurements.

At discharge points required to have air effluent sampling systems, velocity traverse measurements are performed at the traverse points as specified in Method 1. However, because LLNL facilities were constructed and most of the sampling systems were in place before the regulation, the velocity measurements at discharge points not required to have continuous sampling systems may not meet the exact location criteria as specified in Method 1. The TAMM Group Procedure, EMP-AE-SF (LLNL, 1998d) describes the method for conducting velocity traverse measurements at LLNL facilities.

\subsection{Continuous Mass Flow Measurements}

For selected discharge points at some facilities, near-continuous measurements of velocity are made through the employment of permanent electronic velocity, or mass flow, probes. Facilities having mass flow probes include the Building 251 hardened area, Building 331, and Building 332. The continuous mass flow probe systems were placed into service in 1993. At many locations having these systems, the probes have multiple velocity sensors to provide representative measurement of the flow across the duct. In addition, more than one probe may be used to cover the area for rectangular ducts. For probes having multiple sensors, the sensor spacing across the duct was designed to match that of the nozzle spacing used in the corresponding multi-point extraction probes for particulate sampling.

Readings from the sensors are converted to velocity by a microprocessor. The microprocessor also averages the reading from the different sensors and converts the averaged velocity to flow rate. If a sensor fails, the microprocessor removes that sensor from the averaging and displays a warning message on its display. A data logger is used to collect and store the flow rate information. Readings for the exhaust flow rate are collected every $10 \mathrm{~s}$ and are averaged and recorded by the data logger every $2 \mathrm{hr}$ on data storage cards. Data recorded on the storage cards are downloaded periodically into text-formatted files on a computer by TAMM support personnel. The data are later transferred into computer files that are organized by the facility and the exhaust identifier. The flow rate information is then available to be used in conjunction with the activity concentrations as determined from the continuous air samples to estimate radiological emissions.

The velocity sensors in the mass flow probes are calibrated by the manufacturer prior to installation, and are calibrated annually (bi-annually for those at Building 331) in-place using the velocity traverse techniques discussed above. The in-place calibration is conducted by LLNL personnel following the TAMM Group Procedure, EMP-AE-MFC (LLNL, 1998e). 


\subsection{Cyclonic Flow Testing}

The test for cyclonic flow, also described in 40 CFR 60 Appendix A, Method 1, is performed at locations where new sampling systems are to be installed. This method, which measures the flow direction at points in the flow stream, does require the use of the standard S-type pitot tube. The physical characteristics of Pitot tubes used for the measurement are in accordance with the requirements specified in Method 2.

\subsection{NESHAPs Quality Assurance Program}

The quality assurance parameters that are applicable to the NESHAPs program at LLNL are accuracy, precision, and completeness. As defined in paragraph 4.4 of Appendix B 40 CFR 61 Subpart H, accuracy is the degree of agreement of a measurement with a true or known value; precision is a measure of the agreement among individual measurements of the same parameters under similar conditions; and completeness is a measure of the amount of valid data obtained compared to the amount expected under normal conditions. Each of these parameters is discussed in the following sub-sections.

\subsection{Accuracy}

Accuracy can be affected by (1) the degree of representative sampling, (2) maintenance and calibration of samplers, (3) calibration of analytical equipment, and (4) agreement of analytical results with data from standards. At LLNL, air effluent sampling system design conforms to specifications for continuous sampling systems given in ANSI (1969) and in 40 CFR 61 Subpart H. Specifically, all air effluent sampling systems in NESHAPs-monitored facilities meet design specifications, location and sample probe placement criteria, and degree of isokinetic sampling required by 40 CFR 61 Appendix A, Reference Method 1. Operating parameters of the samplers are checked weekly or biweekly, and samplers are calibrated periodically (monthly or annually) according to specified procedures.

With respect to analytical equipment, instrument-resident $\mathrm{QC}$ standards are analyzed with each group of tritium samples measured by the RML. Similarly, each analytical batch of filters includes an alpha- and a betaefficiency check source.

The accuracy of sample analytical results is determined by comparison of samples to known concentrations of analytes. Matrix spikes, i.e., samples prepared in the matrix of interest (e.g., water) with NIST-traceable standards, are used by the RML in their analyses of tritium. (Note: matrix spikes could conceivably be prepared by RML for filters, but this is not currently done.) Sample batches of tritiated water, and filters analyzed for gross alpha and gross beta activity include numerous other analytical standards. A custom 
data reduction and report generation program, Io, automatically compares pre-determined control limits for analytical standards against the sample values obtained in each analytical run. Procedures are in place to prevent the release of analytical data that do not meet QC standards.

\subsection{Precision}

Precision is typically evaluated by assessing the degree of similarity of analytical results from replicate and/or co-located samples. Continuous stack sampling does not readily lend itself to either type of sample, and a direct measurement of the precision of air effluent samples is not available. However, limited indirect data indicate that reasonable precision of air effluent samples is achieved. One of the seven facilities monitored in support of NESHAPs, Building 332, has 12 discharge points equipped with colocated continuous filter samplers and CAMs. For these discharge points, colocated samples are regularly obtained. Similarly, tritium ion chambers, located in each of the stacks at Building 331, yield data on total tritium release levels that supplement data acquired by molecular sieves. These groups of data are regularly evaluated by TAMM analysts for consistency. Specific consideration is given to the number of samples above the LOS for each sampling period and measurement method.

\subsection{Completeness}

Within the context of NESHAPs, completeness applies both to sampling systems and to laboratory analyses of environmental samples. For the continuous stack samplers (simple filter type and molecular sieves), TAMM requires 80 percent completeness of sample collection. That is, over all monitored facilities, samplers must be operational for at least 80 percent of the sampling period. With respect to laboratory analyses, TAMM requires that 90 percent of the samples submitted to, and analyzed by, the HCD laboratories yield valid data. If these completeness criteria are not met, Nonconformance Reports (NCRs) are prepared, as appropriate, and the issue(s) resolved with the Facility, program, and/or laboratory (see Section 15).

\subsection{NESHAPs Quality Control Program}

The NESHAPs Quality Control program encompasses procedures to ensure the integrity of samples and data throughout the processes of sample analysis, data reduction, and data report generation. These, and all other aspects of the Quality Control program are described below in accordance with paragraph 4.5 of Appendix B 40 CFR 61 Subpart H. Section 12 addresses sample handling and sample custody provisions. 


\subsection{Sample Analysis}

Procedures for sample receipt and sample handling have been developed by the RML to minimize the potential for sample contamination, and to ensure accurate tracking of the sample throughout analysis and analytical report generation. These procedures are described in the HCD's Gross Alpha-Beta Procedures Manual (HCD, 1995a) and in the Liquid Scintillation Counting Procedures Manual (HCD, 1997). (The AL does not analyze samples, although laboratory personnel accept and process certain samples prior to analysis by the RML. Procedures for sample handling by the AL are given in HCD $(1996 a, c)$ and in Section 12.)

Four Canberra Model 2400F counters and two Tennelec Model 5500 gas proportional counters are used in the RML for low level alpha/beta counting of air filters. These counters have an 88-sample or a 50-sample capacity, respectively. Sample loading positions for each counter are specified in HCD (1995a), with each tenth position occupied by a sample for the determination of background. Additionally, alpha- and beta-efficiency check sources, and National Institute for Standards and Technology Laboratory (NIST) traceable alpha and beta standards are loaded into the counter and evaluated for each sample batch. HCD (1995a) specifies that chi-square tests be conducted any time that maintenance or any other procedure is performed that could affect gas-proportional counter accuracy. This test consists of conducting 30, twominute counts on both the alpha and beta source standards, and verifying that the values are within desired confidence limits. Voltage plateau tests are performed on the gas proportional counters (as needed) to determine the optimum voltage; test procedures are given in HCD (1995a).

Tritium samples are analyzed by the RML using Beckman liquid scintillation (LS) counters (various models). The Beckman counters are capable of analyzing 336 samples per batch. The RML Liquid Scintillation Counting Procedures Manual (HCD, 1997) designates specific counters for each of the different types of samples (e.g., tritium, swipes) routinely analyzed by the RML. This separation of samples allows individual LS counters to be calibrated for a specific sample type. All LS counters are run with a required set of QC standards; for tritium analyses, twelve QC standards are used (HCD, 1997). These include instrument auto calibration standard(s), tritium quench standards, background samples, a liquid scintillation counting cocktail blank, and a set of tritium and background working standards prepared from NISTtraceable master working solutions.

\subsection{Data Processing}

The RML utilizes a custom data reduction and report generating system, Io. Input to Io is in the form of an American Standard Code for Information Interchange (ASCII) data file. These data files combine the HCD's Sample Tracking and Report (STAR) sample data (see Section 12.0) and RML sample analytical results and associated information. The STAR data 
include sample collection parameters such as sample type, location, and collection date; RML analytical information includes instrument identification, analysis date and time, and both sample and quality control (QC) counting results (see following information). This ASCII file is automatically archived for historical documentation and future reference or recalculation. A software module within the Io system allows the RML Quality Assurance (QA) Advisor to establish, track, and archive individual radiological counting instrument operating and QC parameters.

The Io computer system automatically tracks all radiation counting equipment performance parameters, such as counting efficiency, background levels, and alpha/beta crossover. The limit-of-sensitivity, or minimum detectable count of each sample is calculated by Io using methods and equations given in Homann (1991). Io is also structured to automatically compare predetermined control limits for standards, and for background counts, against the values obtained in each analytical run. After each counting session, an electronic QC Information Report is automatically generated by Io, and is available for review by the RML QA advisor. If any analytical results fall outside of the control limits, no sample data from that run are released, and a Nonconformance Report (NCR) is generated. As deemed appropriate, samples associated with a NCR are re-analyzed after resolution of the source of the discrepancy. Archived NCR reports, each assigned a unique identification number, include a statement of how the QC problem was resolved. When QC parameters for a sample run are within control limits, and the QA Advisor has acknowledged this, Io permits the preparation of sample data reports. All QC reports are archived for reference and documentation.

\subsection{Sample Handling and Custody Provisions}

This section addresses paragraph 4.6 of Appendix B 40 CFR 61 Subpart $\mathrm{H}$ by describing the sample tracking system which has been established to provide for the positive identification of air effluent samples and data through all phases of sample collection, sample analysis, and analytical report

generation. Data management and data analysis procedures are documented in Section 13.

\subsection{Sample Collection and Submittal}

HCD Health and Safety Technologists collect molecular sieves from each of the stacks at Building 331 weekly, based on ES\&H Field Support Instruction Env-3 (LLNL, 1999h). Sieves are placed in a bag, and labeled to indicate the origin of the sample, the equipment identification number, sampling start and stop dates, and sampler flow rate. When the technologist submits the sieves to the AL for extraction, sample delivery is documented in a receiving log notebook maintained by the AL. At the time of sample delivery, the technologist also records the sample data noted above, as well as 
the specific analysis or procedure requested. Samples are tagged with a barcode, and are logged into the HCD STAR system by the technologist. STAR is an ORACLE database application, which provides an electronic method for entering, maintaining, reporting, storing, and tracking sample information. It is a custom application, developed by staff of the HCD (1995b). (Additional details of STAR records and reports are provided in Section 11.2.) If samples are not entered into the STAR database, the AL requires that samples submitted to the laboratory be accompanied by a sample submission sheet (HCD, 1996b).

Air filters requiring direct radiological analyses are collected from building exhaust systems by HCD Health and Safety Technologists under procedures described in ES\&H Field Support Instructions (LLNL, 1999e,f,g). After removal from the sample holder, each air sample filter is placed in a glassine bag for subsequent handling and routing to the RML. Care is taken to avoid cross contamination between samples. Sample bags are labeled with the sample location and sampling start and stop dates, tagged with a unique bar code, and entered into the STAR system by the collecting technologist.

\subsection{Sample Processing}

During sample log-in, STAR records are electronically transferred to the Laboratory Information Management System (LIMS). Alternatively, if sample submission sheets are used, samples are logged into the LIMS manually. In both cases, these information transfers are completed by the AL staff member receiving the sample. The LIMS assigns each sample a unique seven-digit number; this number is entered into the receiving log, and onto the sample container(s) immediately after assignment. The sample identification number is shown on all additional paperwork and/or electronic data tracking of the sample. Other information from the STAR record, such as stack flow rate, analyte(s), final sample or report recipient, etc. are also transferred to the LIMS. The LIMS database was developed by PerkinElmer for use by analytical laboratories, and is used to maintain a permanent record of sample data. Information in the database is backed up daily on permanent media, as well as by the hardcopy file of all documents and papers relating to the samples in the database.

For both the STAR and the LIMS databases, the supporting written record typically consists of the receiving log, submission sheets (if used), notebooks assigned to analysts and/or notebooks dedicated to instruments or assigned to specific activities, procedure manuals, data sheets, reports, and any correspondence related to a given sample.

Tritium collected on molecular sieves is extracted over a three-day period according to HCD analytical procedure HCL-E-2230, Recovery of Tritiated Water From Molecular Sieve Stack Samplers (HCD, 1996c). Samples are transferred to the RML for analysis as described below. The molecular sieves and the extracted water are weighed, and the results recorded in a laboratory notebook. Copies of the appropriate notebook page(s) 
are sent to an Environmental Analyst in the TAMM group on an approximately monthly basis.

It is a policy of the AL to maintain the integrity of samples at all times, and to maintain a record of sample protection when the samples are not under the direct control of laboratory personnel. Details of AL requirements concerning sample handling procedures, maintenance of sample integrity, and sample preservation criteria are given in the quality control manual for the laboratory (HCD, 1996b).

After completion of a set of analyses or extractions, all papers relating to a sample batch are collected and filed in order according to batch number. For tritium extraction data, the AL retains only the submission sheets (if used); all other written records pertaining to these samples are maintained by the RML (HCD, 1996b).

The RML analyzes tritiated water extracted from molecular sieves by the AL using liquid scintillation techniques. Tritium samples prepared by the AL (see preceding discussion) are picked up from the AL by RML staff; sample identification parameters are verified at this time. Transfer of sample custody is documented in the "Radiation Samples Chain of Custody Book"

maintained by the AL. When tritium samples are provided to the RML, they are usually already encoded into the STAR data tracking system (see preceding discussion) (HCD, 1997). If sample data are available only in submission sheets and the LIMS, data are entered into the STAR system at this time. Tritium samples are received from the AL in 20-mL glass vials. The RML analyzes a 1-mL aliquot of each after preparing samples according to procedures described in HCD (1997). Samples are loaded into a specified liquid scintillation counter along with background samples. Each counter also has its own set of calibration and reference standards that are normally left in designated racks in the counters.

Air filter samples are formally 'received' by RML subsequent to verification that sample barcodes correspond to those encoded into the STAR system. This process is documented by completing a HCD RML Sample Receiving Record. After sample receipt by the RML, air filters are brought to holding bins and are held for four days to allow for the decay of naturally occurring radon daughters (HCD, 1995a).

Once filter samples are ready for analysis, they are grouped into batches (i.e., multiple samples to be analyzed by the same procedure), a specific gas proportional counter is selected, and background and calibration sources are loaded in positions as specified in HCD (1995a). Samples are removed from their storage bags, and each bag and the HCD RML Sample Receiving Record is marked with the position the sample will occupy in the counter.

\subsection{Analytical Reporting}

Using the RML software program LOADER, a file is created with a unique file identifier that includes the sample barcode and batch numbers of the samples to be analyzed, along with identification numbers of any quality 
control samples. The sequence of sample entry into this file corresponds exactly to the order that a sample was placed into a given analytical instrument. Once samples are loaded and are ready for analysis, an RML application called DAC (data acquisition) is accessed from a personal computer (PC) that is linked to both the instrument and the main RML PC server. The server assigns a unique 'Run filename' to the analytical run, the instrument PC is initialized to accept data from the instrument into the PC file, and sample analysis begins. Gross alpha and gross beta activity of samples are determined using analytical procedures described in HCD (1995a); tritium is quantified by liquid scintillation counting as per procedures in HCD (1997).

When sample analysis is complete, the PC file is saved and closed out, and an RML application, TRANSFER, is accessed on the instrument PC. The appropriate file is selected, data from that file is transferred to the main RML PC server, and the application, RMLIMS (Radiological Measurements Laboratory Information Management System), is accessed. When given the LOADER batch number, and the DAC filename, RMLIMS accesses the STAR database, the LOADER sample barcode file, and the (DAC) instrument data file. RMLIMS combines the appropriate data from all of these sources into a single Output Report File, which is structured for additional data processing and report generation by the application Io. When accessed and provided with a specific filename, the RML application Io performs any calculations and data reduction, and generates reports which contain sample analysis results. These reports are stored in a "Reports" directory that can be accessed using Microsoft Word. Io also performs a suite of quality control parameter checks and generates a quality control report for each analytical instrument run. Once sample analysis reports have been distributed by the RML and subjected to data verification procedures, electronic results are released for transfer back to the STAR database. A file directory called "RMLin" is accessed by the RML QA/QC coordinator, and the approved files are transferred to a separate directory, "RMLout". A dual RML application STARquery/STARwrite is programmed for automatic operation during nonwork hours to query the appropriate STAR database file and then write the "RMLout" directory files to it. This last process completes the cycle from sample collection, sample analysis, and analytical report generation, to preparation and maintenance of an archived electronic record. Reports that summarize the results of air sample analyses are provided to facility health physicists and to the appropriate Environmental Analyst in the TAMM group of EPD.

\subsection{Data Management and Data Analysis}

Analytical results of air effluent samples are managed and analyzed according to procedures specified by the EPD TAMM Group in LLNL (1998f). These data management and data analysis procedures are discussed in sections 13.1 and 13.2 in accordance with paragraph 4.6 of Appendix B 40 CFR 
61 Subpart H. The policies and procedures that address records management and the control of documents developed in support of the NESHAPs program are discussed in section 13.3. Written reports prepared for the program are described in section 16.0.

\subsection{Data Management}

RML's archived electronic reports, in ASCII format, are structured to contain a month's worth of analytical results for gross alpha and gross beta specific activity (all facilities) or tritium analyses. These records are accessed by a TAMM Group Environmental Analyst, merged, and re-formatted into three files designated STKGROUP, STKAMP, and STKANAL for transfer to the EPD air effluent database. Fields in the STKGROUP file include the sample file number; sample batch number; the identity of both the sample requester and sample submitter; dates of sample analysis and report generation; background alpha and beta activity; and the limits of sensitivity for detection of alpha and beta activity. The STKAMP file contains the sample file number; sample batch number; sample barcode number; sample location data (including building and room number); sample location description; type of sample; type of sampling equipment; sample starting and ending dates; sample volume (and the associated measurement units); analytical liquid volume; molecular sieve water mass; and detector efficiency (the latter three parameters pertain only to tritium analyses). The STKANAL file includes sample file batch number, sample barcode number, analytical method; measured activity; limit of sensitivity, and measurement error.

These files are transferred electronically via e-mail to the Technical Support Group Data Management Team (DMT). Upon receipt by the DMT, data are transferred via Kermit, a file transfer program, to the DMT UNIX directory, and into the air effluent database, STACK. These files are maintained within the EPDDATA database, which contains archives of all routine TAMM Group monitoring data. The air effluent files consist of a cumulative record of radionuclide air emission data from each monitored facility; data are appended to the master file on a monthly basis. Subsequent to entry into STACK, the DMT uploads the files as work tables, and completes a series of automated data verifications for each of the files to ensure and maintain data integrity. These data verification procedures include checks for missing data, the presence of duplicate records, missing equipment identifiers, overlapping sample periods, and the presence of location descriptions. Once data verification procedures have been completed, the work tables are appended to the cumulative STACK file, and output files, in Microsoft EXCEL format are produced. Each of these files contains cumulative air effluent data for each monitored facility. These files are transferred to a TAMM Group Environmental Analyst via electronic mail. The Environmental Analyst verifies the accuracy of the information in these files based on a comparison with hard-copy records of sample barcode number, sample batch number, file number, and sample location 
information. The data verification process also includes a comparison of the information in the electronic files with a tracking file which contains information on sample start and stop dates.

Verified data are retained in electronic form within the EPDDATA database. The database is maintained on a VAX 6310 mainframe. EPDDATA utilizes INGRES v6.4/05, a commercially-available relational database software. INGRES recognizes the Standard Query Language (SQL) for data manipulation but also contains its own forms and reporting tools, allowing secure, electronic access to the data. EPD Computations Support provides both system and software maintenance and application development related to this database. Additional details of the database structure, security and access limitations, data entry procedures, data documentation, and data retrieval capabilities are given in Tate et al. (1999).

\subsection{Data Analysis}

The facility-specific EXCEL output files generated by the DMT are transferred electronically to Environmental Analysts in the TAMM group, and are read via a custom EXCEL Macro into an annual emissions file maintained for each monitored facility. Data contained in these files are analyzed to establish the presence or absence of data from each sampler and each sampling period; data are also incorporated into time-activity plots for each discharge point to facilitate identification of any trend in emissions. For all air effluent results above the minimum detectable concentration, summary statistics i.e., range, mean, and median activity concentrations are calculated.

\subsection{NESHAPs Documents and Records}

LLNL has a comprehensive set of policies that cover the creation, use, maintenance, and storage of records (LLNL, 2000m). In addition, LLNL's Quality Assurance Program for Nuclear Facilities (LLNL, 1998g) stipulates that the quality assurance program of each nuclear facility at LLNL must describe a system that will ensure that facility records are collected, used, and stored in an appropriate manner. All NESHAPs documentation, including input parameter and modeling results for building ventilation stacks, stack/vent emission survey reports, data printouts, emission sampling data, and other related documentation are considered permanent records according to the LLNL Schedule of Records Retention (LLNL, 2000n). These documents are retained in the TSG Document Retention Center as long as the TAMM Group requires immediate access to them, as specified in the NESHAPs Report Guidance Document (LLNL, 2000b). After regular access to these records is no longer required, these records can be stored at the LLNL Records Center and may also be offered to the National Archives and Record Administration.

The TAMM Group has a policy that requires that a formal procedure be written for any technical activity e.g., sample collection, sample processing, 
air-dispersion modeling, etc. These procedures specify the processes required to perform the activity in a standardized, technically-correct manner; they are revised at least every three years. Procedures that have been developed and implemented to address technical requirements of the NESHAPs program at LLNL include EMP-R-DA Guidance for Radiological Dose Assessment (LLNL, 1998c), EMP-AE-SF Effluent Stack Flow Measurement (LLNL, 1998d), EMPAE-MFC Air Effluent Mass Flow Calibration Revision 0 (LLNL, 1998e), EMPAE-DAM Air Effluent Data Analysis and Management, Revision 1 (LLNL, 1998f), and EMP-NS-S NESHAPs Report Guidance Document (LLNL, 2000b).

\subsection{Programmatic Audits}

The NESHAPs Program at LLNL has developed criteria to ensure that formal reviews of program performance are conducted. Specifically, in those years in which either the US EPA or the LLNL Assurance Review Office conduct an audit or inspection of the program, no additional programmatic review will be initiated. However, if an audit or inspection is not scheduled, the TAMM Group is responsible for ensuring that one is completed periodically. The extent of the audit will be determined by the availability of time and funding.

This section documents the requirements of paragraph 4.7 of Appendix B 40 CFR 61 Subpart $\mathrm{H}$ by describing the procedures that exist to perform internal audits, and the results of external audits of both the NESHAPs Program and the HCD Laboratories.

\subsection{Internal Audits}

LLNL's ES\&H Manual Volume I Part 5 (LLNL, 2000o) mandates that each directorate at the Laboratory conduct periodic self-assessments. These assessments cover all organizational components, and facilities and operations, and can include evaluations of safety systems, training, work areas and operations, and compliance with local, state, and federal ES\&H laws and regulations. In addition, the EPD Quality Assurance Management Plan (LLNL, 1993c) establishes the requirements and responsibilities for audits, assessments, surveillances, and other methods of monitoring quality assurance for the Department (of which the TAMM Group is a member). These criteria meet the intent of DOE Order 414.1, Quality Assurance (US DOE, 1999). The audit requirements given in the EPD Quality Assurance Management Plan (LLNL, 1993c) include the criterion that personnel selected as auditors will have appropriate training and experience to conduct the audit. Furthermore, the individual performing the audit must be independent of any direct responsibility for performance of the activity they will evaluate.

Procedures for the conduct of assessments (audits), and to establish the requirements for the qualification and certification of persons performing 
these audits are formalized in EPD Quality Implementing Procedure (QIP) QIP-18.1 (LLNL, 1992b) and QIP-18.2 (LLNL, 1993d), respectively.

\subsection{External Audits}

External audits relevant to the NESHAPs program include both direct programmatic audits (Section 14.2.1), and audits of the laboratories that analyze air effluent samples collected from continuously-monitored buildings (Section 14.2.2).

\subsubsection{NESHAPs Program Audits}

In 1991, the DOE and the US EPA began developing a Federal Facilities Compliance Agreement (FFCA). This agreement contained a plan and a schedule for DOE/LLNL to demonstrate and maintain compliance with requirements of 40 CFR 61 Subpart $\mathrm{H}$, the National Emission Standards for Hazardous Air Pollutants (NESHAPs) other than Radon from Department of Energy Facilities (US EPA, 1991). The FFCA was signed by representatives of the US EPA and DOE in August of 1993. In accordance with the FFCA, DOE and LLNL agreed to provide quarterly reports on the progress made in the evaluation of LLNL's facilities for compliance with 40 CFR 61 Subpart H, until such time as compliance could be demonstrated. In the spring of 1994, following submission of eight quarterly reports to the US EPA, LLNL was notified that all requirements of the FFCA had been met (US EPA, 1994b).

In 1996, US EPA Region IX representatives conducted a Compliance Evaluation Investigation of the NESHAPs program at LLNL. During the course of the inspection, US EPA representatives requested and received information on building ventilation systems; location of stack monitoring and/or sampling systems; and stack flow velocity measurement techniques. US EPA personnel toured the HCD laboratories and were given detailed information concerning laboratory operations and capabilities; participation of the HCD laboratories in laboratory intercomparison programs (see details later in this section); techniques used to analyze air effluent samplers; data tracking and data management protocols; and laboratory quality assurance. HCD personnel from the Industrial Hygiene Instrument Laboratory (IHIL) provided information on HEPA filter testing, including details of test procedures, testing frequency, documentation of test results, and record keeping. LLNL was found to be in compliance with 40 CFR 61 Subpart H, and no additional compliance activities were required (US EPA, 1996).

In 1997, US EPA Region IX representatives conducted a NESHAPs Compliance Evaluation Investigation at Site 300. During this investigation, LLNL personnel made a number of presentations which provided the US EPA with information on explosives tests air dispersion modeling assumptions and calculations, diffuse source modeling calculations for Site 300, the planned operations of the Contained Firing Facility, and the onsite tritium and air particulate monitors. In a letter report to LLNL, the US EPA 
indicated that the Site 300 facility met the requirements of 40 CFR 61 Subpart $\mathrm{H}$, and that no additional compliance activities were required (US EPA, 1997).

During 1999, the Assurance Review Office of LLNL conducted an assessment of the radiological NESHAPs program at LLNL using qualified auditors both from within and external to LLNL. The purpose of that assessment was to determine whether programmatic activities are conducted in a manner consistent with demonstrating Laboratory compliance with 40 CFR 61 (LLNL, 1999i). The Assessment Team found that the radiological NESHAPS compliance activities at LLNL were satisfactory, and that management of the program by the TAMM Group was conducted in a manner that allowed for the independent verification of compliance activities.

However, the Team also reached certain Findings concerning the NESHAPs program at LLNL, where a Finding is defined as a "...statement(s) of fact regarding a condition of noncompliance with a regulatory, statutory, LLNL, or internal administrative control requirement" (LLNL, 1999i). These Findings have been entered into LLNL's Deficiency Tracking System (see Section 15.1) for tracking and resolution. The Assessment Team also listed a number of Concerns, defined as "... statements of opinion regarding a perceived vulnerability; they typically describe situations involving less than optimal performance and/or a condition which if not corrected could lead to noncompliance." (LLNL, 1999i). The Concerns identified by the Team are being addressed by an action plan developed within ORAD. The Team concluded that the Findings and Concerns regarding the NESHAPs program at LLNL did not " ... indicate any immediate or significant impacts on: the overall level of compliance with the requirements of 40 CFR 61 Subpart H or the reliability of data used for calculation of the annual effective dose equivalent".

\subsubsection{HCD Laboratory Audits}

The HCD Laboratories (i.e., the AL and the RML) participate in the DOE Environmental Monitoring Laboratory (EML) Inter-comparison Studies program. The EML administers a Quality Assessment Program designed to test the quality of environmental radiological measurements reported by DOE contractor and sub-contractor laboratories. DOE mandates participation in the program for laboratories that conduct work in support of DOE environmental radiological monitoring programs (US DOE 1988b). Under the auspices of the EML, HCD Laboratories receive air filters for analysis of gross alpha and gross beta activity twice a year. Data from the HCD Laboratories participation in the EML program in 1998 (the most recent published data) indicate that all ten samples from the EML were within established acceptance control limits (Harrach et al., 1998).

The State of California accredits the AL and RML for gross alpha and gross beta analysis of air filters, as well as for analysis of tritium by liquid scintillation counting. 
The Quality Control Manual for the AL (HCD, 1996b) stipulates that a detailed audit of laboratory operations shall be performed every other year by a team of one or more auditors having authority independent of the AL staff. Those auditors may include the American Industrial Hygiene Association, the California Department of Health Services (DHS), the EPD or other LLNL department. In those years when no audit is performed by an outside agency, a quality assurance audit is performed by a person designated by the Safety Laboratories Division Leader (HCD, 1996b). Reports resulting from each audit, including information on the scope of the audit and deficiencies found (if any), are provided to the Safety Laboratories Division Leader, as well as to appropriate technical staff (HCD, 1996b).

\subsection{Corrective Action Program}

Lawrence Livermore National Laboratory, EPD, the TAMM Group of the Operations and Regulatory Affairs Division, and the RML of the HCD each have plans and/or procedures which address nonconformance and discrepancy reporting, and the conduct of corrective actions. This section describes the relevant components of each plan, and the responsibilities of the organizations and/or individuals that are involved in accordance with the requirements of paragraph 4.8 of Appendix B 40 CFR 61 Subpart H.

\subsection{Lawrence Livermore National Laboratory}

Programmatic and/or procedural deficiencies identified during directorate self-assessments (see Section 14.1) are recorded and tracked within the LLNL Deficiency Tracking System (DefTrack). [The Deficiency Tracking System is a custom relational database application that provides a mechanism for collecting data, tracking corrective action and status, making independent verification, and analyzing trends (LLNL, 1995b).] The LLNL Assurance Review Office conducts independent reviews of each directorate's ES\&Hrelated activities. These appraisals address issues such as the implementation of specific Laboratory programs (e.g., NESHAPs) and compliance with environmental regulations. Necessary corrective actions identified by these appraisals are also tracked on the Deficiency Tracking System.

As specified in LLNL's ES\&H Manual (LLNL, 2000o), the deficiencies identified in operations and facilities during self-assessments, evaluations, and/or appraisals are reviewed by the cognizant management to determine appropriate corrective actions. Line managers assign responsibility for implementing actions to correct identified deficiencies, and use DefTrack to monitor the status until the corrective actions are completed and verified. Findings and recommendations from appraisals, audits, and reviews of operations are documented in reports and entered into DefTrack where appropriate.

LLNL also has an Occurrence Reporting Program, developed to meet the requirements of DOE Order 232.1A, Occurrence Reporting and Processing 
of Operations Information (US DOE, 1997). Requirements of that Order include the stipulation that a written report of an occurrence (i.e., an adverse event or condition) be prepared for DOE. That report must contain an analysis of the event, as well as a delineation of appropriate corrective action(s) and the responsibilities for implementation.

\subsection{Environmental Protection Department}

The EPD operates under a both the LSO Quality Assurance Plan (LLNL, 1999j) and a Departmental Quality Assurance Management Plan (LLNL, 1993c) that establish the policies and procedures to be met by Department personnel in planning, performing, documenting, and verifying qualityaffecting activities.

In the TAMM Group of ORAD, the procedures for identification and resolution of most discrepancies or nonconforming activities are provided in ORAD-QA-NCR, Nonconformance Reporting and Tracking (LLNL, 1997g). ORAD-QA-NCR identifies specific issues and/or circumstances that require the preparation of a NCR. These include, but are not limited to, lost samples, incorrect sampling method, equipment malfunctions, interruption of utility services, human error in sampling, and samples lost or contaminated by an analytical laboratory. Activities not covered by this procedure include selfassessment corrective action plans, items listed in DefTrack, and data errors discovered during the Site Annual Environmental Report Quality Control check. These latter activities are covered in separate procedures referenced in LLNL (1997g).

\subsection{Radiological Measurements Laboratory}

The RML of HCD utilizes the custom computer application, Io, to automatically summarize analytical data, track all radiation counting equipment performance parameters, and compare control limits for analytical and background standards against sample results for each analytical run. This system, described in Section 12.0, is structured to generate a QC Information Report after each analytical run, and to automatically produce a Nonconformance Report and QC Failure Report if results are outside of specified control limits. Procedures for correction and resolution of problems associated with generation of these reports are also described in Section 12.0.

\subsection{Reporting}

This section addresses the requirements of paragraph 4.9 of Appendix B 40 CFR 61 Subpart $\mathrm{H}$ by describing the reports which are prepared in support of, or incorporate data from, the NESHAPs program at LLNL. Information on each of these reports is provided in the following discussion. 


\subsection{NESHAPS Annual Reports}

The LLNL NESHAPs Annual Report is the primary informationsource document of the radiological NESHAPs program at LLNL, and contains data on all NESHAPs-related activities conducted at LLNL during a given calendar year. Prepared by the TAMM Group of EPD, each year's report contains updated estimates of annual radionuclide emissions, by isotope, for active RMMA's at LLNL (e.g., Gallegos et al., 1998). The report also provides radionuclide emissions estimations from areas or facilities where operations began in the preceding year, along with supporting information that describes the general nature of the new operations. For all areas and facilities at LLNL where radioactive materials are used, or where activation products occur, data are also provided on physical-state factors of each isotope, stack parameters, emission control devices and the corresponding abatement factors. The NESHAPs Annual Report presents the results of dose-assessment modeling runs conducted for point sources and diffuse sources. These assessments are based on either actual measured radionuclide releases to air, or potential releases based on radionuclide usage inventory data. The annual dose to the site-wide maximally-exposed member of the public is calculated from these data.

The NESHAPs Annual Report discusses the status of the quality assurance program, and provides specific information on programmatic quality control. For example, in 1997, confirmatory sampling evaluations of two NESHAPs discharge points were conducted (see Gallegos et al., 1998). For these discharge points, it was determined that neither of the sources was a significant contributor to the LLNL site dose, and that continuous monitoring was not required by regulation. Also in 1997, a comparison was made between CAP88-PC modeling runs completed for the three most significant sources of tritium releases to air at the Livermore site, and surveillance air monitoring data for all eleven tritium air monitors on the Livermore site and one off-site tritium air monitor. This comparison demonstrated that there is good agreement of the modeling and surveillance data for all of the monitors.

\subsection{Tritium Facility Report}

Environmental Analysts in the TAMM Group also prepare a quarterly letter report containing tritium release data from Building 331 for the most recent three-month period (e.g., Tate, 1997). The report contains weekly emission totals of molecular tritium (HT) and tritiated water (HTO) for each of the two stacks; cumulative individual totals of HT and HTO; cumulative combined $(\mathrm{HT}+\mathrm{HTO})$ weekly totals; and cumulative combined $(\mathrm{HT}+\mathrm{HTO})$ totals. Emission data are also presented graphically to facilitate an evaluation of the presence of any trend in tritium releases from the facility.

\subsection{Sitewide Annual Environmental Report}


The sitewide annual Environmental Report (SAER) (e.g., Harrach et al., 1998) provides analytical results from all of LLNL's environmental monitoring and compliance sampling, as well as an assessment of the impact of LLNL's operations on the environment and the public. The SAER contains a chapter on air effluent monitoring at LLNL; data in this chapter are obtained from the NESHAPs program, but are summarized differently than in the NESHAPs Annual Report to address the separate regulatory requirements under which the SAER is prepared. For example, the SAER presents a compilation of annual isotope-specific emissions from all sources at LLNL, as well as an estimate of the total calculated emissions (all radionuclides) for the year. Where the specific isotopic content of usage inventories is not known, gross alpha and gross beta activities are reported. For those facilities monitored under NESHAPs, annual summaries, by facility and individual sampler number, of gross beta activity, gross alpha activity, or tritium releases are also given.

\subsection{Environmental Monitoring Plan}

The Environmental Monitoring Plan (EMP) (Tate et al., 1999) is prepared tri-annually to meet requirements of DOE Order 5400.1, General Environmental Protection Program Requirements (US DOE, 1988b). That Order requires a written environmental monitoring plan for each DOE site, facility, or process that uses, generates, releases, or manages significant pollutants or hazardous materials. The EMP provides information on the characteristics of the sampling and monitoring systems in place at each monitored facility, number of samplers, frequency of sample collection, and the analytical methods used to quantify radionuclide releases. NESHAPs program Quality Assurance, programmatic responsibilities, and supporting documentation are described. Separate sections in the EMP describe and reference Quality Assurance documents, procedures, and requirements for laboratories that provide analytical services to the TAMM Group, which administers the NESHAPs program at LLNL. These laboratories include the $\mathrm{AL}$ and the RML of the HCD, which perform the extraction of tritium from molecular sieves (AL), and liquid scintillation counting and analysis of gross alpha and gross beta activity on air effluent filter samplers (RML). The EMP also describes Quality Assurance Criteria applicable to TAMM Group personnel, including performance standards for documents and records, work processes, and inspection and acceptance testing (Tate et al., 1999).

\subsection{Occurrence Reporting}

Unplanned radionuclide releases have in the past been the subject of occurrence reporting to the DOE. Guidelines for the occurrence reporting of radioactive releases to the environment are provided in the LLNL implementing procedures for DOE Order 232.1A, Occurrence Reporting and Processing of Operations Information (LLNL, 1998h; US DOE, 1997). For 
example, within the context of NESHAPs, an unplanned release of radionuclides would be reported as an occurrence if the release was at a concentration, or led to an exposure, that exceeds the $10 \mathrm{mrem} / \mathrm{y}$, maximum allowable whole body EDE to members of the public (40 CFR 61).

The FSP for the Tritium Facility (LLNL, 1997d) requires that planned, unplanned, or suspected releases of $5 \mathrm{Ci}$ or more of tritium within a 24-hour period must be reported to the Deputy Associate Director for Operations in accordance with the most recent version of the Defense Systems Nuclear Design Program Occurrence Reporting Protocol (see LLNL, 1997d). No specific radionuclide release quantities have been established by any of the other facilities monitored under NESHAPs, or by the TAMM Group, which would mandate the submittal of an occurrence report.

\subsection{Department of Energy Quality Assurance Program Requirements}

DOE Order 414.1 (US DOE, 1999) establishes management performance requirements for all DOE facilities by delineating Quality Assurance (QA) Program criteria. 10 CFR 830.120c, Quality Assurance Criteria (Federal Register, 1999) addresses management practices and principles for Nuclear and Radiological Facilities, and establishes a set of QA criteria for these facilities. The criteria of DOE Order 414.1 (US DOE, 1999) and 10 CFR 830.120c (Federal Regulations, 1999) were developed to ensure protection of workers, the public, and the environment. Both regulations require that a QA plan be developed, implemented, and maintained in accordance with the specific requirements of these regulations. These QA requirements apply to facilities monitored under NESHAPs, and may also apply to the NESHAPs program. However, many of the criteria for the QA plans, as well as the other QA criteria contained within these regulations, are identical to those of 40 CFR 61 Subpart $\mathrm{H}$, and have been addressed in one or more preceding sections of this document (see Appendix A for a table that cross-references QAP requirements). Those QA plan requirements that are unique to DOE Order 414.1 (US DOE, 1999) or 10 CFR 830 (Federal Register, 1999) are addressed in this section.

\subsection{Personnel Training and Qualification}

In response to requirements of 10 CFR 830 (Federal Register, 1999), LLNL's Quality Assurance Program for Nuclear Facilities (LLNL, 1998g) stipulates that each nuclear facility develop, implement, and maintain a written QA plan; LLNL (1998g) also identifies the principles and requirements for personnel training and qualifications at the Laboratory's nuclear facilities. Facilities currently monitored under NESHAPs that are also subject to the requirements of that document are Buildings 251, 331, and 332. 
DOE Order 414.1 (US DOE, 1999) includes Personnel Training and Qualification as a specific criterion of the QA program requirements applicable to all non-nuclear DOE facilities. That criterion stipulates that personnel must be trained and qualified to ensure they can adequately perform their work, and that they be provided with continuing training to ensure continued job proficiency.

LLNL's Training Program Manual (LLNL, 1998i) establishes training policies for all job-related training at the Laboratory, including training designed to meet operational needs, state and federal laws and regulations, DOE orders, and University of California guidelines. The manual also delineates the mechanisms LLNL has established to ensure that required training is accomplished, and provides guidelines on implementing the training program.

The Environmental Protection Department (EPD) provides technical assistance to all LLNL Facilities with respect to environmental compliance, Three separate groups within the Operations and Regulatory Affairs Division of EPD have specific responsibilities to the NESHAPs program (see section 2.3.3). Training for all EPD personnel is governed by The Laboratory Site Operations Training Implementation Plan (LLNL, 1991) in general, and by the Environmental Protection Department Training Management Plan (LLNL, 2000p) in particular. The EPD Training Management Plan (LLNL, 2000p) addresses responsibilities, training requirements, verification of employee qualification and re-qualification, record keeping and self-assessment. EPD also maintains a NESHAPs Agreement of Roles and Responsibilities with the Hazards Control Department (LLNL, 2000d). That Agreement includes an acknowledgement that the Hazards Control Department is responsible for providing the training to $\mathrm{H} \& \mathrm{~S}$ Technologists who perform activities integral to the NESHAPs program such as air effluent sample collection, transport of samples to the appropriate analytical laboratory for analysis, field calibration of measuring devices, and other related tasks.

\subsection{Design Criteria}

The Quality Assurance Program criteria listed in DOE Order 414.1 (US DOE, 1999) and 10 CFR 830 (Federal Register, 1999) include identical lists of standards developed to ensure that (1) the design of items and processes is conducted in accordance with sound engineering and scientific principles; (2) design work incorporates applicable requirements and design bases; (3) that interfaces are identified and controlled; (4) that products are independently verified or validated, and (5) that validation and verification work must be completed before approval and implementation of the design. Similar design standards are given in LLNL (1998g), LLNL's Quality Assurance Program for Nuclear Facilities.

According to the NESHAPs Agreement(s) of Roles and Responsibilities (LLNL, 2000d,e,f,g,h), EPD is responsible for providing guidance to facilities and programs on the design of air sampling systems. In meeting this 
responsibility, the NESHAPs program is committed to providing design guidance in accordance with the standards given in LLNL (1998g), US DOE (1999), and the Federal Register (1999). 


\subsection{References}

American Society of Mechanical Engineers (ASME) (1989) "Nuclear Power Plant Air-Cleaning Units and Components," ASME N509-1989.

American National Standards Institute (ANSI) (1969) "Guide to Sampling Airborne Radioactive Materials in Nuclear Facilities," ANSI N13.1-1969.

Biermann, A. H. and Bergman, W. (1988) "Filter Penetration Measurements Using a Condensation Nuclei Counter and an Aerosol Photometer," J. Aerosol Sci., V19, pp. 471-483.

Burchsted, C., Fuller, A., and J. Kahn (1979) "Nuclear Air Cleaning Handbook," US Government Printing Office, Washington DC, ERDA 76-21.

Calibration and Standards Laboratory (CSL) (1996) Eberline Alpha-5/5A Continuous Air Monitor (CAM) and Eberline Alpha-3 Continuous Air Monitor (CAM), Calibration Procedures, Calibration and Standards Laboratory, Safety Laboratories Division, Hazards Control Department, Lawrence Livermore National Laboratory, Livermore CA, February 1996.

Federal Register (1980), "Interim Status Standards for Owners and Operators of Hazardous Waste Treatment, Storage, and Disposal Facilities," Code of Federal Regulations 40, Part 265.

Federal Register (1985), "Release Reporting and Notification Requirements," Code of Federal Regulations 40, Part 302.6.

Federal Register (1987), "SARA Title III Emergency Planning and Notification," Code of Federal Regulations 40, Part 355.

Federal Register (1989), "National Emission Standards for Hazardous Air Pollutants; National Emission Standards for Emissions of Radionuclides Other Than Radon from Department of Energy Facilities," Protection of Environment, Code of Federal Regulations 40, Part 61, Subpart H.

Federal Register (1993a), "Occupational Radiation Protection," Code of Federal Regulations 10, Part 835.

Federal Register (1993b), "Continuous Emission Monitoring," Code of Federal Regulations 40, Part 75, Subpart H.

Federal Register (1996), “Hazardous Waste Operations and Emergency Response," Code of Federal Regulations 29, Part 1910.120. 
Federal Register (1998), "Federal Radiological Emergency Response Plan, Code of Federal Regulations Title 50, Part 46.

Federal Register (1999), “Nuclear Safety Management," Code of Federal Regulations Title 10, Volume 4, Part 830.

Gallegos, G., A. Biermann, Harrach, R., Bertoldo, N., Hall, L., Surano, K., and R. Berger (1998) "LLNL NESHAPS 1997 Annual Report," Environmental Protection Department, Operations and Regulatory Affairs Division, Lawrence Livermore National Laboratory, Livermore CA, UCRL-ID-11386798.

Harrach, R., Larson, J., Gallegos, G., Christofferson, Brandstetter, E., Tate, P., Biermann, A., Fields, B., Garcia, L., and P. Althouse (1998), "Environmental Report 1997", Lawrence Livermore National Laboratory, Livermore, CA, UCRL-50027-97.

Hazards Control Department (HCD) (1995a) Radiological Measurements Laboratory (RML) Gross Alpha-Beta Procedures Manual, Revision 2, Hazards Control Department, Lawrence Livermore National Laboratory, Livermore, CA, October 30, 1995.

Hazards Control Department (HCD) (1995b), "Sample Tracking and Reporting System (STAR), HIT User's Manual Chapter 4", Management Information Systems Team (MIST), Hazards Control Department, February 8, 1995.

Hazards Control Department (HCD) (1996a) Radiological Measurements Laboratory Quality Assurance Implementation Plan, Safety Laboratories Division, Hazards Control Department, May 2, 1996.

Hazards Control Department (HCD) (1996b) Analytical Quality Control Manual, Safety Laboratories Division, Hazards Control Department, November 12, 1996.

Hazards Control Department (HCD) (1996c) "Recovery of Tritiated Water from Molecular Sieve Stack Samplers," Procedure HCL-E-2230, May 28, 1996.

Hazards Control Department (HCD) (1997) Radiological Measurements Laboratory LSC, Liquid Scintillation Counting Procedures Manual, Revision 1, Hazards Control Department, Lawrence Livermore National Laboratory, Livermore CA, July 11997.

Homann, S. (1991) "Limit of Sensitivity of Low-Background Counting Equipment." Lawrence Livermore National Laboratory, Livermore CA, UCRL-ID-106314. 
Hoover, M.D. and G.J. Newton (1991) “Technical Bases for Selection and Use of Filter Media in CAMS for Alpha Emitting Radionuclides," in Inhalation Toxicology Research Institute Annual Report for 1990-1991, LMF-134, December 1991. Inhalation Toxicology Research Institute, Albuquerque NM.

Industrial Hygiene Instrument Laboratory (IHIL) (1996) “HEPA Filter Test Procedure," Procedure No. HEPA 1.0 (Rev. 4), Industrial Hygiene Instrument Laboratory, Safety Laboratory Division, Hazards Control Department, Lawrence Livermore National Laboratory, Livermore, CA, November 19, 1996.

Lawrence Livermore National Laboratory (LLNL) (1991) "Laboratory Site Operations Training Implementation Plan", Laboratory Site Operations, Lawrence Livermore National Laboratory, Livermore CA.

Lawrence Livermore National Laboratory (LLNL) (1992a) "Memorandum from Abel Garcia, Plutonium Facilities Manager, to Bill Isherwood, Environmental Monitoring and Analysis Division, regarding Air Effluent Radionuclide Monitoring for Building 332 in Compliance with NESHAPs (National Emission Standards for Hazardous Pollutants) and the Clean Air Act", PuF092-734/11g, November 17, 1992.

Lawrence Livermore National Laboratory (LLNL) (1992b) “Environmental Protection Department Quality Implementing Procedure QIP-18.1, Assessments" Environmental Protection Department, Lawrence Livermore National Laboratory, Livermore CA, December 8, 1992.

Lawrence Livermore National Laboratory (LLNL) (1993a) “Memorandum to George Campbell, Department Head, Hazards Control Department, from Harry L. Galles, Department Head, Environmental Protection Department, regarding Environmental Support Team Charter and Protocol", October 26, 1993 ORAD 93-073.

Lawrence Livermore National Laboratory (LLNL) (1993b) "Memorandum to Bill Isherwood, Environmental Monitoring and Analysis Division, from Clayton Lagerquist, B-251 Facility Manager regarding Air Effluent Radionuclide Monitoring for B-251 in Compliance with NESHAPs (National Emission Standards for Hazardous Pollutants) and the Clean Air Act", March 3 1993, Cl-NCD93-45.

Lawrence Livermore National Laboratory (LLNL) (1993c) "Environmental Protection Department Quality Assurance Management Plan, Revision 3", Environmental Protection Department, Lawrence Livermore National Laboratory, Livermore CA, October 151993. 
Lawrence Livermore National Laboratory (LLNL) (1993d) “Environmental Protection Department Quality Implementing Procedure QIP-18.2, Requirements for Qualifications of Persons Performing Quality Assessments", Environmental Protection Department, Lawrence Livermore National Laboratory, Livermore CA, October 11993.

Lawrence Livermore National Laboratory (LLNL) (1995a) “Defense and Nuclear Technologies Directorate, Plutonium Facility - Building 332, Safety Analysis Report, Volumes 1 and 2," Lawrence Livermore National Laboratory, Livermore CA, UCRL-AR-119434.

Lawrence Livermore National Laboratory (LLNL) (1995b) “Deficiency Tracking System (DefTrack) Policy and Procedures Manual, Version 2, Assurance Review Office", Lawrence Livermore National Laboratory, Livermore CA, May 1995.

Lawrence Livermore National Laboratory (LLNL) (1997a) "Facility Safety Procedure 175, Building 175 Complex MARS Facility", Lawrence Livermore National Laboratory, Livermore CA, February 1997.

Lawrence Livermore National Laboratory (LLNL) (1997b) "Facility Safety Procedure, Building 490-S Complex, Separation Demonstration Facility", Lawrence Livermore National Laboratory, Livermore, CA, February 1997.

Lawrence Livermore National Laboratory (LLNL) (1997c) "Facility Safety Procedure, Building 251", Lawrence Livermore National Laboratory, Livermore, CA, July 1997.

Lawrence Livermore National Laboratory (LLNL) (1997d) "Facility Safety Procedures Tritium Facility Building 331". Lawrence Livermore National Laboratory, Livermore, CA.

Lawrence Livermore National Laboratory (1997e) "Building 331 Self-Help Plan, Defense and Nuclear Technologies, TF97-031," Lawrence Livermore National Laboratory, Livermore CA, April 1997.

Lawrence Livermore National Laboratory (1997f) Building 331 Tritium Monitor Alarms Maintenance Manual, Lawrence Livermore National Laboratory, Livermore, CA, internal document.

Lawrence Livermore National Laboratory (LLNL) (1997g), “ORAD-QA-NCR, Nonconformance Reporting and Tracking, Revision 0", Operations and Regulatory Affairs Division (ORAD), ORAD Division SOP, Lawrence Livermore National Laboratory, Livermore CA, September 1997. 
Lawrence Livermore National Laboratory (1998a) "Plutonium Facility — Building 332 Facility Safety Procedure," FSP-332-96 (w/Change 1), Lawrence Livermore National Laboratory, Livermore CA, April 1998.

Lawrence Livermore National Laboratory (LLNL) (1998b), "Environmental Satellite Operations Center Operations Manual, Revision 9", Lawrence Livermore National Laboratory, Livermore, CA, internal document.

Lawrence Livermore National Laboratory (LLNL) (1998c), “EMP-R-DA, Guidance for Radiological Dose Assessment," Terrestrial and Atmospheric Monitoring and Modeling Group, Lawrence Livermore National Laboratory, Livermore, CA, April 31998.

Lawrence Livermore National Laboratory (LLNL) (1998d) “EMP-AE-SF, Air Effluent Stack Flow Measurement, Revision O", Terrestrial and Atmospheric Monitoring and Modeling Group, Lawrence Livermore National Laboratory, Livermore CA, April 1998.

Lawrence Livermore National Laboratory (LLNL) (1998e) "EMP-AE-MFC, Air Effluent Mass Flow Probe Calibration, Revision O", Terrestrial and Atmospheric Monitoring and Modeling Group, Lawrence Livermore National Laboratory, Livermore CA, April 1998.

Lawrence Livermore National Laboratory (LLNL) (1998f) "EMP-AE-DAM, Air Effluent Data Analysis and Management, Revision 1", Terrestrial and Atmospheric Monitoring and Modeling Group, Lawrence Livermore National Laboratory, Livermore CA, December 4, 1998.

Lawrence Livermore National Laboratory (LLNL) (1998g), “Quality Assurance Program for Nuclear Facilities, Revision 4, and LLNL Implementation Plan, Revision 4," M-078-NF Rev. 4, Lawrence Livermore National Laboratory, Livermore CA, March 1998.

Lawrence Livermore National Laboratory (LLNL) (1998h), "Lawrence Livermore National Laboratory Implementing Procedures for DOE Order 232.1A, Occurrence Reporting and Processing of Operations Information, Revision 1.2" Lawrence Livermore National Laboratory, Livermore, CA, March 1998.

Lawrence Livermore National Laboratory (LLNL) (1998i), "Training Program Manual," UCRL-MA-106166, Rev 6, Lawrence Livermore National Laboratory, Livermore CA, April, 1998. 
Lawrence Livermore National Laboratory (LLNL) (1999a) "Shutdown, Surveillance, and Maintenance Plan for AVLIS Facilities," Lawrence Livermore National Laboratory, A-059010-01, Livermore CA, May 1999.

Lawrence Livermore National Laboratory (LLNL) (1999b) "Physics Directorate Integrated Safety Management System Handbook, Lawrence Livermore National Laboratory, Livermore, CA, October 21 1999. Electronic document accessible at http:/ /www-phys.llnl.gov/llnl_only/SafetySupportGroup/ISM_Handbook.html

Lawrence Livermore National Laboratory (LLNL) (1999c) "Health Physics Discipline Action Plan, ES\&H Team 1, Facilities: 331, 334, 337, 338", Lawrence Livermore National Laboratory, Livermore, CA, December 1999.

Lawrence Livermore National Laboratory (LLNL) (1999d) "Health Physics Discipline Action Plan, ES\&H Team 1, Facilities: 332, 335", Lawrence Livermore National Laboratory, Livermore, CA, December 1999.

Lawrence Livermore National Laboratory (LLNL) (1999e) "Environmental Safety and Health (ES\&H) Field Support Instruction", Environmental Protection Department, Environmental Discipline Action Plan, ES\&H Team 3, Facilities: 251, 261, 263, 1482, 2632, Lawrence Livermore National Laboratory, Livermore, CA, December 1999.

Lawrence Livermore National Laboratory (LLNL) (1999f) "Environmental Safety and Health (ES\&H) Field Support Instruction", Environmental Protection Department, Environmental Discipline Action Plan, ES\&H Team 1, Facilities: 332, 335, Lawrence Livermore National Laboratory, Livermore, CA, December 1999.

Lawrence Livermore National Laboratory (LLNL) (1999g) "Environmental Safety and Health (ES\&H) Field Support Instruction", Environmental Protection Department, Environmental Discipline Action Plan, ES\&H Team 2, Facilities: 175, 177, 273, 482, 490, 491, 492, 493, 494, 495, 1736, 1738, 3724, 3725, 3726, 3751, 3775, 3777, 5925, 5926, 5928, 5975, 5976, 5977, 5978, 5981, 5982, 5983, 5984, 5985, Lawrence Livermore National Laboratory, Livermore, CA, December 1999.

Lawrence Livermore National Laboratory (LLNL) (1999h) “Environmental Safety and Health (ES\&H) Field Support Instruction", Environmental Protection Department, Environmental Discipline Action Plan, ES\&H Team 1, Facilities: 331, 334, 337, 338, Lawrence Livermore National Laboratory, Livermore, CA, December 1999. 
Lawrence Livermore National Laboratory (LLNL) (1999i) "Assessment of LLNL Compliance with the National Emission Standards for Hazardous Air Pollutant Standards (NESHAPs) for Emission of Radionuclides from DOE Facilities," Assurance Review Office, Lawrence Livermore National Laboratory, ARO 99-02, Lawrence Livermore National Laboratory, Livermore CA, May 1999.

Lawrence Livermore National Laboratory (LLNL) (1999j) “Laboratory Site Operations Quality Assurance Plan", October 1999, electronic document accessible at http://www-r.llnl.gov/lso/eshga/QAP/quality.html

Lawrence Livermore National Laboratory (LLNL) (2000a) “The Environmental Safety and Health (ES\&H) Manual, Volume III: Environment - Hazards and Controls Part 1: Air" March 2000, electronic document accessible at hyperlink http://www.llnl.gov/es_and_h/ecm/chapter_12/chap12.html\#12.3 http://www.llnl.gov/es_and_h/ecm/chapter_12/chap12.html\#12.3

Lawrence Livermore National Laboratory (LLNL) (2000b), “EMP-NS-S, NESHAPs Report Guidance Document," Operations and Regulatory Affairs Division, Livermore National Laboratory, Livermore CA, March 242000.

Lawrence Livermore National Laboratory (LLNL) (2000c) "The Environmental Safety and Health (ES\&H) Manual, Volume I: ES\&H Management" March 2000, electronic document accessible at http://wwwr.llnl.gov/es_and_h/esh-manual/volume1.html

Lawrence Livermore National Laboratory (LLNL) (2000d) "NESHAPs Agreement of Roles and Responsibilities, Hazards Control Department and Environmental Protection Department", Lawrence Livermore National Laboratory, Livermore, CA.

Lawrence Livermore National Laboratory (LLNL) (2000e) "NESHAPs Agreement of Roles and Responsibilities, Laser Directorate and Environmental Protection Department", Lawrence Livermore National Laboratory, Livermore, CA.

Lawrence Livermore National Laboratory (LLNL) (2000f) "NESHAPs Agreement of Roles and Responsibilities, Heavy Element Facility and Environmental Protection Department", Lawrence Livermore National Laboratory, Livermore, CA.

Lawrence Livermore National Laboratory (LLNL) (2000g) "NESHAPs Agreement of Roles and Responsibilities, Tritium Facility and 
Environmental Protection Department", Lawrence Livermore National Laboratory, Livermore, CA.

Lawrence Livermore National Laboratory (LLNL) (2000h) "NESHAPs Agreement of Roles and Responsibilities, Plutonium Facility and Environmental Protection Department", Lawrence Livermore National Laboratory, Livermore, CA.

Lawrence Livermore National Laboratory (LLNL) (2000i) "The Environmental Safety and Health (ES\&H) Manual, Volume I, Part 2, "ES\&H Management Requirements", March 2000, Electronic document accessible at http://www.llnl.gov/es_and_h/esh-manual/volume1.html\#s2.

Lawrence Livermore National Laboratory (LLNL) (2000j) “The Environmental Safety and Health (ES\&H) Manual, Volume II, Part 10, "Emergencies, Earthquakes, Fire", March 2000, Electronic document accessible at http://www.llnl.gov/es_and_h/esh-manual/volume2.html\#s10.

Lawrence Livermore National Laboratory (LLNL) (2000k) "The Environmental Safety and Health (ES\&H) Manual, Volume II, Part 13, "General Controls--Safety Systems", March 2000, Electronic document accessible at hyperlink http://www.llnl.gov/es_and_h/eshmanual/volume2.html\#s13 http://www.llnl.gov/es_and_h/eshanual/volume2.html\#s13 .

Lawrence Livermore National Laboratory (LLNL) (20001) "The Environmental Safety and Health (ES\&H) Manual, Volume III, Part 6, Waste", Lawrence Livermore National Laboratory, Livermore CA, March 2000, Electronic document accessible at hyperlink http://www.llnl.gov/es_and_h/esh-manual/volume3.html\#s6

http://www.llnl.gov/es_and_h/esh-manual/volume3.html\#s6 .

Lawrence Livermore National Laboratory (LLNL) (2000m) “Lawrence Livermore National Laboratory Records Management Policy Guide," hyperlink https://wwwais.llnl.gov/llnl_only/docs/bsd/records/rmpolicy.html https://wwwais.llnl.gov/llnl_only/docs/bsd/records/rmpolicy.html

Lawrence Livermore National Laboratory (LLNL) (2000n) “Lawrence Livermore National Laboratory Schedule of Records Retention", April 2000, electronic document accessible at hyperlink https://wwwais.llnl.gov/llnl_only/docs/bsd/records/retention/10/10-02-020.html 
https://www-ais.llnl.gov/llnl_only/docs/bsd/records/retention/10/10-02$\underline{020 . h t m l}$

Lawrence Livermore National Laboratory (LLNL) (2000o) “The Environmental Safety and Health (ES\&H) Manual, Volume I, Part 5, "Feedback \& Improvement", March 2000, Electronic document accessible at http://www.llnl.gov/es_and_h/esh-manual/volume1.html\#s5.

Lawrence Livermore National Laboratory (LLNL) (2000p) “Environmental Protection Training Department Training Management Plan, Revision 2", DRAFT, Environmental Protection Department, Lawrence Livermore National Laboratory, Livermore CA, April 2000.

Ostlund, H.G. and A.S. Mason (1974) "Atmospheric HT and HTO I.

Experimental Procedures and Tropospheric Data 1968-72," Tellus XXVI, pp. 91-101.

Sharry, J., Beason, D., and R. Goin (1997) “Emergency Plan 1993", Lawrence Livermore National Laboratory, Livermore, CA, UCRL-MA-113311 Rev. 2.

Tate, P. (1997) Memorandum from Paula Tate, Operations and Regulatory Affairs Division to J.M. Mintz, regarding B-331 Routine Tritium Report, May 30, 1997.

Tate, P., Mathews, S., Gallegos, G., Garcia, L., Larsen, J., Biermann, A., Brandstetter, E., Christopherson, E., Harrach, R., Rueppel, D., Gouveia, F., Althouse, P., Fields, B., MacQueen, D., Brown, R., Vellinger, R., Surano, K., Folks, K., Brigdon, S., Grayson, A., Hoppes, W., Welsh, R., Cannon, G., Berger, R., Blake, R., Taffet, M., Failor, R., and C. Choate (1999) "Environmental Monitoring Plan," Operations and Regulatory Affairs Division, Lawrence Livermore National Laboratory, Livermore CA UCRL-ID-106132 Rev. 2.

University of California (1998) "University of California Laboratory Procurement Policy and Standard Practices Manual," Electronic document accessible at http://labs.ucop.edu/internet/sps/sps.html 
US Department of Energy (US DOE) (1988a) DOE Order 5820.2A Radioactive Waste Management.

US Department of Energy (US DOE) (1988b) DOE Order 5400.1 General Environmental Protection Program Requirements.

US Department of Energy (US DOE) (1991) DOE Order 5530.1A Accident Response Group.

US Department of Energy (US DOE) (1992a) DOE Order 5530.3 Radiological Assistance Program.

US Department of Energy (US DOE) (1992b) DOE Order 5530.5 Federal Radiological Monitoring and Assessment Center.

US Department of Energy (US DOE) (1993a) DOE Order 5400.5 Radiation Protection of the Public and the Environment.

US Department of Energy (US DOE) (1993b) DOE Order 5610.14 Transportation Safeguards System Program Operations.

US Department of Energy (US DOE) (1995a) Memorandum of Understanding (MOU) with the Environmental Protection Agency (EPA) Concerning the Radionuclide National Emission Standards for Hazardous Air Pollutants (NESHAPs), Department of Energy, San Francisco Office, Environment, Safety, and Facility Operations Division, April 5, 1995.

US Department of Energy (US DOE) (1995b) DOE Order 151.1 Comprehensive Emergency Management System.

US Department of Energy (US DOE) (1997) DOE Order 232.1A Occurrence Reporting and Processing of Operations Information.

US Department of Energy (US DOE) (1999) DOE Order 414.1 Quality Assurance.

US Environmental Protection Agency (US EPA) (1991), Federal Facility Compliance Agreement, Docket No. 9-91-17, United States Environmental Protection Agency Region IX in the matter of United States Department of Energy, San Francisco Operations Office, Lawrence Livermore National Laboratory, Livermore CA.

US Environmental Protection Agency (US EPA) (1993), Memorandum from Jon Richards, United States Environmental Protection Agency, Region IX, to Shelly Rosenblum, United States Environmental Protection Agency, Region 
IX, regarding Region IV Comments on LLNL's Request for Certain Alternative Procedures. December 281993.

US Environmental Protection Agency (US EPA) (1994a), EPA Requirements for Quality Assurance Program Plans for Environmental Operations, EPA QA/R-5, United States Environmental Protection Agency, Quality Assurance Division, Washington DC, Draft Interim Final, August 1994.

US Environmental Protection Agency (US EPA) (1994b), Memorandum from David P. Howekamp, Director, Air and Toxics Division, United States Environmental Protection Agency Region IX, to Terry A. Vaeth, Acting Manager, United States Department of Energy, Oakland Operations Office, Oakland, CA., regarding Lawrence Livermore National Laboratory's satisfactory demonstration of compliance with all requirements of the Federal Facility Compliance Agreement, Docket No. 9-91-17.

US Environmental Protection Agency (US EPA) (1996), Memorandum from Michael S. Bandrowski, Director, Office of Radiation and Indoor Air, United States Environmental Protection Agency Region IX, to Lois Marik, Chief, Terrestrial and Atmospheric Monitoring and Modeling Group, US Department of Energy, Oakland Operations Office, Oakland CA, regarding the Compliance Evaluation Investigation performed at Lawrence Livermore National Laboratory on May 28, 1996.

US Environmental Protection Agency (US EPA) (1997), Memorandum from Michael S. Bandrowski, Director, Office of Radiation and Indoor Air, United States Environmental Protection Agency Region IX, to Kris Surano, Leader Terrestrial and Atmospheric Monitoring and Modeling Group, Lawrence Livermore National Laboratory, regarding the NESHAP 40 CFR 61, Subpart H Compliane Evaluation Investigation performed at the Lawrence Livermore National Laboratory, Site 300 on September 3, 1997. 


\title{
Appendix A. Department of Energy Quality Assurance Program Requirements ${ }^{\mathrm{a}}$
}

\author{
DOE Quality Assurance Criterion
}

\section{Location of Information in this QAPP}

\author{
Program
}

Sections 2.4; 17

Personnel Training and Qualifications

Section 17.1

Quality Improvement

Sections 14, 15

Documents and Records

Sections 13.3, 16

Work Processes

Sections 8,9,12,13 


\section{Design}

Section 17.2

Procurement

Section 4.2 .2

Inspection and Acceptance Testing

Sections 8,9

Management Assessment

Section 14.1

Independent Assessment

Section 14.2

${ }^{a}$ US DOE (1999) and Federal Register (1999). 